Article

\title{
Design Optimization of a Composite Solar Wall Integrating a PCM in a Individual House: Heating Demand and Thermal Comfort Considerations
}

\author{
Enghok Leang, Pierre Tittelein $₫$, Laurent Zalewski * ${ }^{\circledR}$ and Stéphane Lassue \\ Laboratoire de Génie Civil et géo-Environnement (LGCgE), Université d'Artois, ULR 4515, \\ F-62400 Béthune, France; enghok.leang@univ-artois.fr (E.L.); pierre.tittelein@univ-artois.fr (P.T.); \\ stephane.lassue@univ-artois.fr (S.L.) \\ * Correspondence: laurent.zalewski@univ-artois.fr
}

Received: 23 September 2020; Accepted: 21 October 2020; Published: 28 October 2020

\begin{abstract}
Thermal energy storage (TES), which features an innovative technology, can enhance energy efficiency in the building sector and reduce $\mathrm{CO}_{2}$ emissions. Due to their high heat storage capacity, phase change materials (PCMs) have impressed many researchers. This paper investigates the energy performance of an individual house integrating a solar Trombe wall containing PCM with respect to heating demand and thermal comfort applications. The thermal energy performance of the design house was simulated using Dymola/Modelica, the thermal building simulation tool, whereby the optimization of objective functions as regards heating demand and thermal comfort was executed using GenOpt, the generic optimization software. Optimization of the solar Trombe wall focuses on the feasibility to find the optimal PCM parameters when running GenOpt, which consist of latent heat, melting temperature, PCM thickness and thermal conductivity, in order to minimize both the annual energy consumption for heating and the number of hours of thermal discomfort. The parametric study was first conducted for each PCM parameter so as to not only observe its effect on the identified energy performance, but also ensure the absence of errors in simulation runs before performing the optimization. The 'Coordinate Search' Generalized Pattern Search (GPS) algorithm was applied to minimize the objective function, whereas the 'Weighted Sum Approach' was used to solve the multi-objective function problem. Results showed that the higher the latent heat, the lower the heating demand and the greater the thermal comfort. The results of these parametric studies show that for the effect of the parameter on heating, demand is quite limited $\left(1-2 \mathrm{kWh} \cdot \mathrm{m}^{-2} \cdot \mathrm{year}^{-1}\right)$ whereas the effect on thermal comfort is more significant. The optimal PCM melting temperature is higher for warmer climates; it is also higher for the studied case applying the optimization method to minimize the objective function by assigning the number of hours of thermal discomfort (from $32.8^{\circ} \mathrm{C}$ to $35.9^{\circ} \mathrm{C}$, depending on weather) than it is when applying the optimization method to reduce the objective function by assigning heating demand (from $31.5^{\circ} \mathrm{C}$ to $32.9^{\circ} \mathrm{C}$, again depending on weather).
\end{abstract}

Keywords: individual house; solar composite Trombe wall; phase change material; Dymola/ Modelica; GenOpt

\section{Introduction}

Buildings are responsible for roughly $40 \%$ of EU energy consumption and $36 \%$ of its $\mathrm{CO}_{2}$ emissions [1]; it is the single largest energy consumer category in Europe. A package of energy efficiency measures (EEMs), under the guidelines of European regulations (EU) [2,3], has established various building measures to mitigate consumption, including building envelope improvements, passive techniques, building system modifications as well as measures based on sustainable energy 
sources. A solar Trombe wall that integrates a phase change material (PCM), which is the focus of the present study, is a passive design technique that may be considered as an EEM.

When a numerical model of a system is developed and integrated into a building model, the ystem design can be improved so as to achieve better building energy performance. Parametric studies can be conducted; with this method, varied inputs of each variable expose the impact on the objective functions, while all other variables are held constant. This methodology is frequently time-consuming since it requires iterative repetition with other variables to achieve a dual purpose: observe the objective results; and recognize that its results will only be an incomplete improvement due to complex and nonlinear interactions of input variables on simulation results [4]. To derive an optimal or near-optimal solution to a problem with less manual time, the computerized building model is typically solved by iterative techniques for developing infinite sequences of continuously better approximations to a "solution", i.e., finding a point in the search space that satisfies an optimality condition [4]. Due to the iterative nature of this methodology, such methods, commonly known as 'numerical optimization' or 'simulation-based optimization' [5], are typically automated by means of computer programming. The reviews regarding the optimization of thermal building design have been discussed in previous papers, including: a review of computational optimization methods applied to renewable and sustainable energy [6,7]; a review of the optimization of passive solar design strategies concerning the more commonly used thermal building simulation tools, with optimal solutions to a multi-objective design [8]; a review of simulation-based optimization approaches and commonly used algorithms applied to building performance analysis [5,9]; a literature review of papers on improving the energy performance of residential buildings [10]; a review paper on simulation-based optimization in building envelope design based on the most widespread algorithms and well-known optimization software tools [11,12]; and a review specifically dedicated to the energy performance optimization of existing buildings [13].

Simulation-based optimization has become a cost-effective method accommodating many extreme necessities of high-performance buildings, e.g., low-energy buildings, passive houses, green buildings, net zero energy buildings, zero-carbon buildings. It entails the use of a computer-automated model, in which a thermal building energy simulation program is combined with an algorithmic optimization engine. In this way, the optimization problem is solved using iterative methods driven by optimization algorithms [9] that build orders of increasingly improved approximations to reach a 'solution', which in reality is a point satisfying an optimality condition inside the search space. In this work, Dymola/Modelica [14], the dynamic thermal simulation program for buildings to analyze thermal and energy behavior, is coupled with the Generic Optimization program GenOpt ${ }^{\circledR}$ [15].

A thermal building simulation program coupled with optimization approaches requires considerable processing resources and computation time since a yearly building simulation relies upon numerous parameters, inherent in both the complexity of the building model (e.g., number of thermal zones, building components, simulation alternatives) and the chosen simulation engine. To obtain an optimal or near-optimal solution, a typical optimization analysis requires anywhere from a small number to a few thousand evaluations, thus resulting in running times that can last from a few minutes to hours or even days until an acceptable solution is reached. To decrease the simulation runtime, both the appropriate optimization algorithm and specific applied techniques need to be taken into consideration.

Optimization refers to an approach to find the minimum or maximum value of a function with respect to a selection of various variables subject to various constraints. The optimization function, also known as cost function or objective function, is typically determined with the help of simulation tools. The use of a specific optimization method that does not rely on computing function derivatives is necessary since some code features may be directed towards nonlinearities and discontinuities [9]. Optimization methodologies can be implemented in various building model problems, e.g., building envelope, orientation, fenestration and facade design, plus thermal comfort, daylighting, energy needs for heating and/or cooling and construction costs. 
GenOpt ${ }^{\circledR}$ is a rather commonly used tool in the building optimization method according to the results of interviews with building optimization experts [16]. The GenOpt program runs on the source code in JAVA and is a free generic optimization tool built to execute building optimization problems (BOPs); it is thereby appropriate and reasonable to use in building performance simulations (BPS) with an acceptable level of complexity. Furthermore, GenOpt is an optimization tool to minimize the objective function $f(\cdot)$, as evaluated from external simulation tools that read its input from text files and write its output to text files, e.g., EnergyPlus [17], TRNSYS [18], Dymola/Modelica. Choosing optimization algorithms for a particular study condition serves to reach the optimal cost function value, leading to the best cost reduction [19]. Hence, the methodology for choosing an optimization algorithm in a given BOP normally depends on various considerations, such as design variables, constraints and nature of objective functions, analytical first- and second-order derivatives of the objective functions, static vs. dynamic problem and potential algorithm performance [20].

Building optimization studies that select the cost function as an objective to minimize can be performed based on both the single and multi-objective approaches. Nonetheless, the single-objective approach, i.e., comprising just one objective function, can be optimized in a simulation-based optimization ( $60 \%$ of building optimization investigations have used the single-objective method [7]). In any case, designers frequently need to juggle, in real-world building optimization problems, with more than one objective function to optimize and simultaneously contradictory design problems, e.g., minimum energy consumption vs. maximum thermal comfort, minimum energy consumption vs. minimum construction cost. Therefore, multi-objective optimization is, in many cases, more efficient and applicable than the single-objective method [21,22]. Two well-known methodologies typically exist for multi-objective optimization problems: weighted sum, and a Pareto front result. Using a weighted sum function is one method, whereby each of the objectives is simplified and summed along with its related weight factor in order to obtain just one cost function. The simplified approach to solving a multi-objective problem is known as "scalarization"; its purpose is to first assign individual weighting factors to each criterion, then the objective function will be the weighted sum of all the criteria [23]. In other words, this multi-objective optimization will transform into a single-objective problem by means of linear scalarization.

The previous work [24] studied the impact on the heating demands of integrating a solar wall in a single-family dwelling and the number of hours of thermal discomfort based on several types of composite solar walls. This study reveals the conceivable effect of relating the thermal energy storage (TES) of PCM during charging and discharging as a heating supply source during the heating period to the reference study case of a house without a solar Trombe wall. The energy needs for space heating and the number of hours of thermal discomfort were determined in this study by seeking an objective function of energy performance leading to optimal energy consumption.

The literature contains many relevant studies regarding the optimization of solar Trombe walls: optimization of the type and thickness of the Trombe wall core layer by means of EnergyPlus, GenOpt and a parametric algorithm [25]; combination method between the Life Cycle Assessment (LCA) approach and the factorial plan technique to design and optimize energy and environmental performance [26]; and optimization of a Trombe wall system using TRNSYS and the Life Cycle Cost (LCC) criterion [27]. At the same time, optimization studies have also been carried out with respect to optimal PCM, with the aim of improving building energy performance: optimization study of the latent heat of PCM integrated into external building walls [28]; multi-objective optimization methods for the energy retrofitting of office buildings integrated with PCM-enhanced opaque building envelope components [29]; an analytical approach detecting the optimal PCM melting temperature in a passive solar room [30]; optimization of PCM melting temperature to enhance conservation energy [31]; simulation-based optimization of PCM melting temperature using EnergyPlus and GenOpt to enhance the energy performance in buildings [32]; optimization analysis of a PCM-enhanced opaque building envelope for energy retrofitting [29]; optimization of a building envelope integrating PCM for nearly zero-energy buildings (nZEBs) [33]; and the application of PCM 
for retrofitting existing buildings [34-36]. The implementation of PCM can also optimize the level of $\mathrm{CO}_{2}$ emission. Some of the previous literature studies regarding the PCM to reduce $\mathrm{CO}_{2}$ level have been conducted [37-41]. It is interesting therefore to study the building energy performance based on a simulation-based optimization within an approach coupling the solar Trombe wall with PCM for the purpose of maximizing building performance.

Qingsong M. et al. [42] conducted an analytical optimization of a ventilated composite Trombe wall in the energy performance of an office building. The purpose of their study was to optimize the power supplied from a ventilated Trombe wall using a dynamic thermal load calculation tool (THERB for HAM) for heating applications in winter. The outcome from this optimized ventilation within a Trombe wall led to the reduction of annual energy costs by up to $3.7 \%$ compared to non-optimized ventilation. Tamara B. et al. [43] used 3D numerical CFD analysis to simulate and optimize the thermal impact to the energy requirement of a Trombe wall integrated into a passive house. The optimization of the resultant Trombe wall was based on the various parametric simulations in alternating different types of glazing placed at the exterior side of the wall. The energy savings reported in the analytical studies were in reality obtained. Milorad B. et al. [25] optimized the energy and environmental performance of two passive Trombe walls placed on the south side of a house located in Lyon, France by means of coupling EnergyPlus as a thermal energy simulation tool with the GenOpt parametric algorithm as a generic optimization engine. The optimal parameters to be determined consisted of: (1) the optimal size of the Trombe wall; and (2) the optimal combination of glass, frame and core material composing the Trombe wall. The objective function was to minimize the annualized life cycle primary energy for heating. The output revealed an energy savings for heating on the order of $20 \%$ compared to the building without Trombe walls. Francesca S. et al. [26] used an LCA approach, a thermal simulation tool and analytical optimization based on a factorial plan method to optimize a solar Trombe wall in terms of its various wall materials and design features. The optimal result showed that the cumulative energy demand of solar walls for both production and use could be reduced by up to $55 \%$, while it was simultaneously feasible to minimize the $\mathrm{CO}_{2}$ as well.

However, according to the aforementioned review performed by the authors, no research has targeted the simulation-based optimization of a solar Trombe wall incorporating a PCM. Some of the investigations discussed above regarding optimization are simply the analytical and parametric studies on optimization that have yielded an incomplete and/or partial improvement in results. Consequently, a scientific gap exists in improving the thermal performance of the solar Trombe wall integrating PCM into the building applications that lead to minimizing the energy consumed for purposes of heating/cooling and maintaining thermal comfort.

This study aims to bridge the scientific gap indicated above as regards implementing and optimizing PCM within a solar Trombe wall integrated into an individual house located in northern France. It further investigates the possibilities of applying the simulation-based optimization approach, coupling Dymola/Modelica, the thermal building simulation tool, with the generic optimization GenOpt, towards energy efficiency measures (EEMs) using sustainable energy to minimize the annual energy consumption inside buildings. The secondary objectives of this study are to identify the parametric studies pertaining to the effect of four thermal properties of PCM, i.e., latent heat $\mathrm{LA}_{\mathrm{pcm}}$, melting temperature $\mathrm{TM}_{\mathrm{pcm}}$, storage wall thickness $\mathrm{e}_{\mathrm{pcm}}$ and thermal conductivity $\lambda_{\mathrm{pcm}}$, and to establish the simulation-based optimization methodology targeting the following objective functions: heating demand objective function, number of hours of thermal discomfort objective function and heading demand + number of hours of discomfort objective function.

\section{Methodology}

\subsection{Description of the House Model}

The model and its main characteristics have already been presented in previous work [24] and validated in [44]. The thermal behavior of the house was modeled using the 'MixedAir' component 
of the 'Modelica Buildings Library' [45], in connecting a solar Trombe wall model developed by our team and presented in [24]. The 'MixedAir' component, which contains heat transfer via opaque and non-opaque elements like walls, ceilings, floors and windows, can be utilized to simulate the single or multi-zone model. Air flowing inside the room is mixed, while air circulating between zones is neglected. Furthermore, a total airflow of $150 \mathrm{~m}^{3} / \mathrm{h}$ is assigned for the whole house according to the standard [46]. Schematic diagram of this house model has been shown in previous works [24].

Figure 1 shows the schematic architectural view of the detached house, which comprises three thermal zones: the coupling zone on the north side of the house, with a total area of $30.39 \mathrm{~m}^{2}$; the $11.13 \mathrm{~m}^{2}$ bedroom on the south side; and the $24.25-\mathrm{m}^{2}$ living room on the south side. The constructive features of this detached house as well as the physical characteristics of its elements are given in the table of the previous work [24].

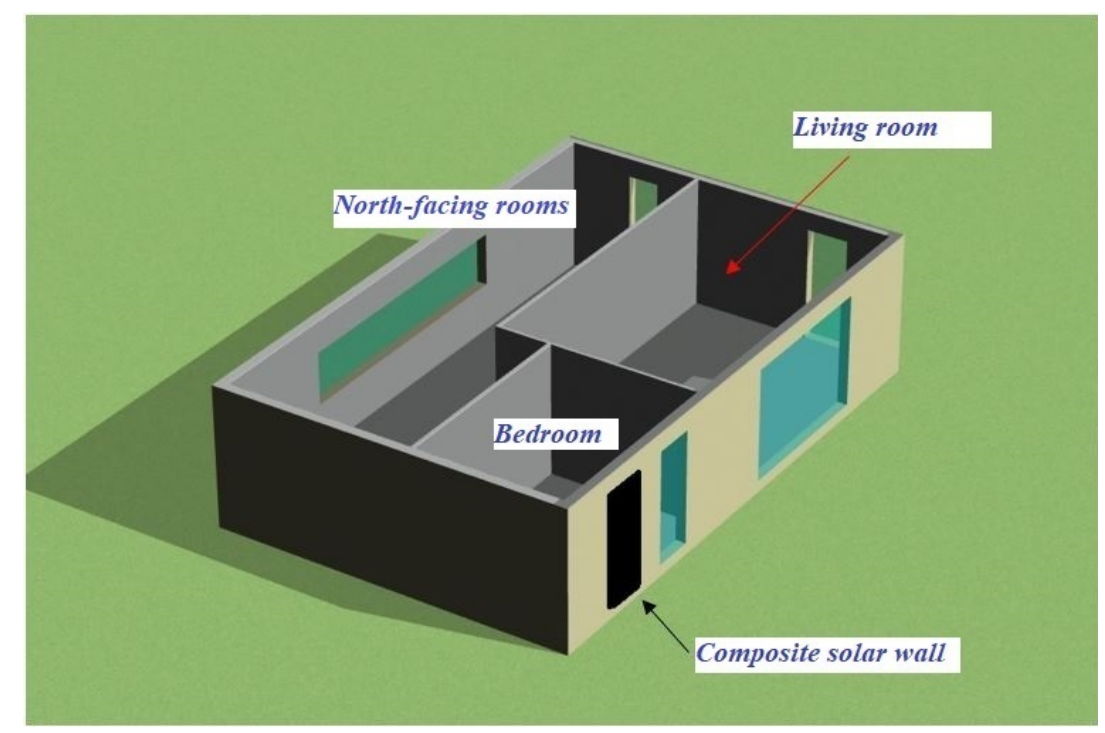

Figure 1. Schematic depiction of the detached single-family house.

The window features integrated into the zoning are composed of double-glazing with an air gap of $12 \mathrm{~mm}$ between $4-\mathrm{mm}$ thick glass panes and a low-emissivity thin coating. The frame area as a proportion of the total window area equals $38 \%\left(\mathrm{U}_{\mathrm{fr}}=0.38\right)$. Window area and orientations have been reported in the previous work [24].

\subsection{Solar Trombe Wall Description and Climatic Regions}

Figure 2 shows the vertical cross-section of the solar Trombe wall. The system consists of the PCM storage wall, with a total area of $2.88 \mathrm{~m}^{2}$ (1.34 $\mathrm{m}$ wide by $2.15 \mathrm{~m}$ high), double glazing on the exterior and an insulating panel on the interior. The storage wall is a composite material including cement mortar and $17 \%$ by mass of microencapsulated Micronal BASF 5001 DX ${ }^{\circledR}$, generating a latent heat of $17.1 \mathrm{~kJ} / \mathrm{kg}$. The phase change temperature is $25.8^{\circ} \mathrm{C}$. The characterization of the thermal properties of the composite storage wall has been described in [47]. The thermal characteristics of the element used in the solar Trombe wall system are listed in table of the previous study [24]. The numerical study of the solar Trombe wall integrated along with the concrete and PCM storage wall, compared to the results of measurement data, were validated in previous studies [44,48]. It should be noted herein that the solar Trombe wall, installed at the southern wall of the house model, is exposed to both sunlight and outside air. 


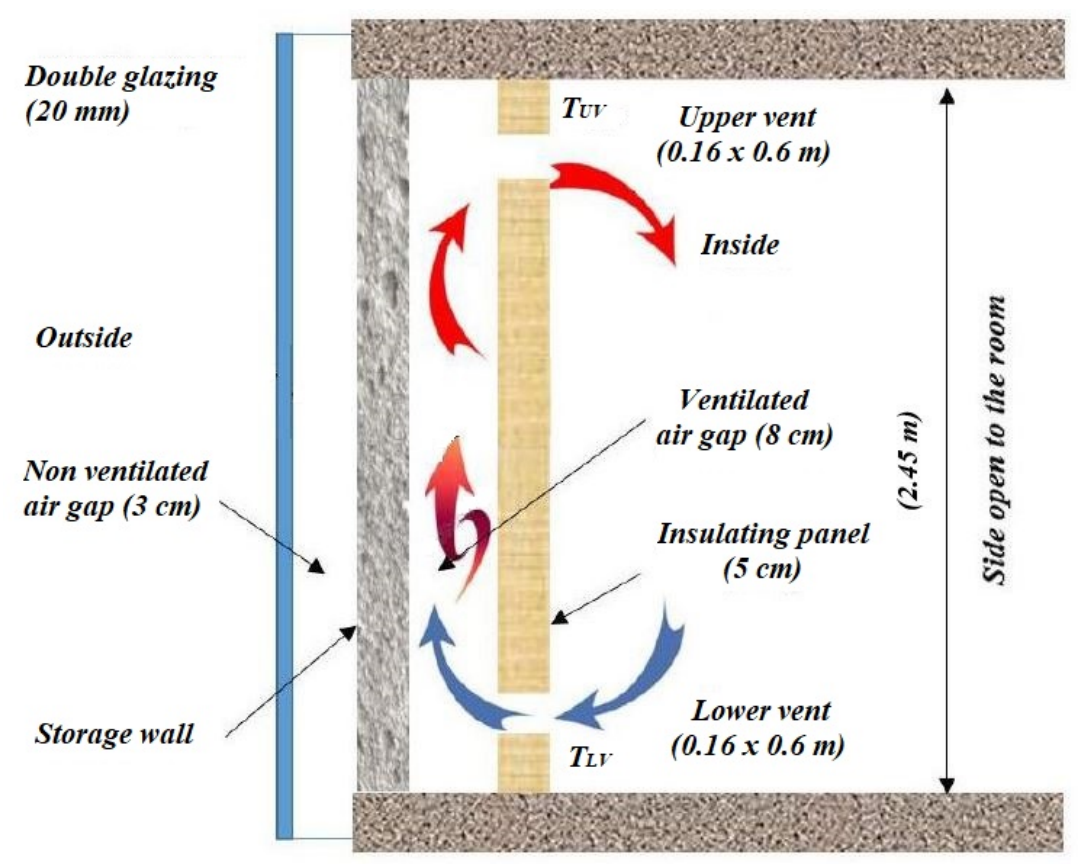

Figure 2. Vertical cross-section of the solar Trombe wall system.

Three weather files used in the simulation have been extracted from the "EnergyPlus" software website [49]. Table 1 shows the meteorological parameters specific to the monthly maximum of the global solar flux and the monthly average outside air.

Table 1. Meteorological parameters for Paris-Orly, Lyon and Nice (France).

\begin{tabular}{|c|c|c|c|c|c|c|c|c|c|c|c|c|c|}
\hline Weather & Variable & January & February & March & April & May & June & July & August & September & October & November & December \\
\hline \multirow{2}{*}{ Paris } & $\phi,\left(\mathrm{W} / \mathrm{m}^{2}\right)$ & 154 & 253 & 366 & 523 & 588 & 649 & 671 & 627 & 481 & 334 & 198 & 135 \\
\hline & $\mathrm{T},\left({ }^{\circ} \mathrm{C}\right)$ & 3.9 & 4.2 & 7 & 10 & 14.3 & 16.8 & 19.4 & 19.7 & 15.7 & 11.3 & 6.4 & 4.7 \\
\hline \multirow{2}{*}{ Lyon } & $\phi,\left(\mathrm{W} / \mathrm{m}^{2}\right)$ & 185 & 324 & 493 & 583 & 623 & 713 & 760 & 659 & 561 & 339 & 214 & 161 \\
\hline & $\mathrm{T},\left({ }^{\circ} \mathrm{C}\right)$ & 3.3 & 3.8 & 7.9 & 10.8 & 15.4 & 19 & 21.6 & 20.4 & 16.4 & 13 & 7.3 & 4 \\
\hline \multirow[b]{2}{*}{ Nice } & $\phi,\left(\mathrm{W} / \mathrm{m}^{2}\right)$ & 314 & 432 & 541 & 675 & 724 & 779 & 841 & 793 & 636 & 439 & 327 & 273 \\
\hline & $\mathrm{T},\left({ }^{\circ} \mathrm{C}\right)$ & 9 & 8.8 & 11.5 & 13.1 & 17.5 & 20.6 & 23.9 & 24 & 20.8 & 16.2 & 11.8 & 9.2 \\
\hline
\end{tabular}

\section{Parametric Study}

Before proceeding with the optimization of solar Trombe wall parameters, it is important to understand the impact of each PCM parameter on the thermal performance of the solar Trombe wall at the building scale. The parameters considered herein relate to the characteristics of the composite material (mortar $+\mathrm{PCM}$ ): the latent heat $\mathrm{LA}_{\mathrm{pcm}}$, the melting temperature $\mathrm{TM}_{\mathrm{pcm}}$ and the thermal conductivity $\lambda_{\text {pcm. }}$. The variation in PCM thickness eppcm is also taken into account. Table 2 shows the definition, established range and value steps to be optimized. The bounds were chosen one-by-one to be physically plausible (since not all combinations are realistic). It should be noted that once a parametric study has been conducted, all the other parameters are held at their basic value, as given in the "Base" column of Table 2.

Table 2. Solar Trombe wall parameters: definition, respective ranges and steps.

\begin{tabular}{ccccccc}
\hline Parameter & Definition & Units & Minimum & Base & Maximum & Steps \\
\hline$L A_{p c m}$ & latent heat & $\mathrm{J} / \mathrm{kg}$ & 10,000 & 17,100 & 40,000 & 1000 \\
$T M_{p c m}$ & melting temperature & ${ }^{\circ} \mathrm{C}$ & 18.8 & 25.8 & 55.8 & 1 \\
$e_{p c m}$ & storage wall thickness & $\mathrm{m}$ & 0.04 & 0.04 & 0.15 & 0.01 \\
$\lambda_{p c m}$ & thermal conductivity & $\mathrm{W} /(\mathrm{m} \cdot \mathrm{K})$ & 0.2 & 0.62 & 1 & 0.05 \\
\hline
\end{tabular}




\section{Effect of Solar Wall Parameters on Heating Demand}

\subsection{Variation in Latent Heat (LA_pcm)}

First of all, Figure 3 shows that the heating demand varies by $1 \mathrm{kWh} \cdot \mathrm{m}^{-2} \cdot \mathrm{year}^{-1}$ within the defined range of latent heat. It further indicates that as the latent heat increases, the energy supplied by the solar Trombe wall decreases; paradoxically, heating demand also decreases. To fully understand this phenomenon, it is necessary to more accurately analyze the effect of a latent heat increase on the indoor temperature and the power being released by the solar Trombe wall.

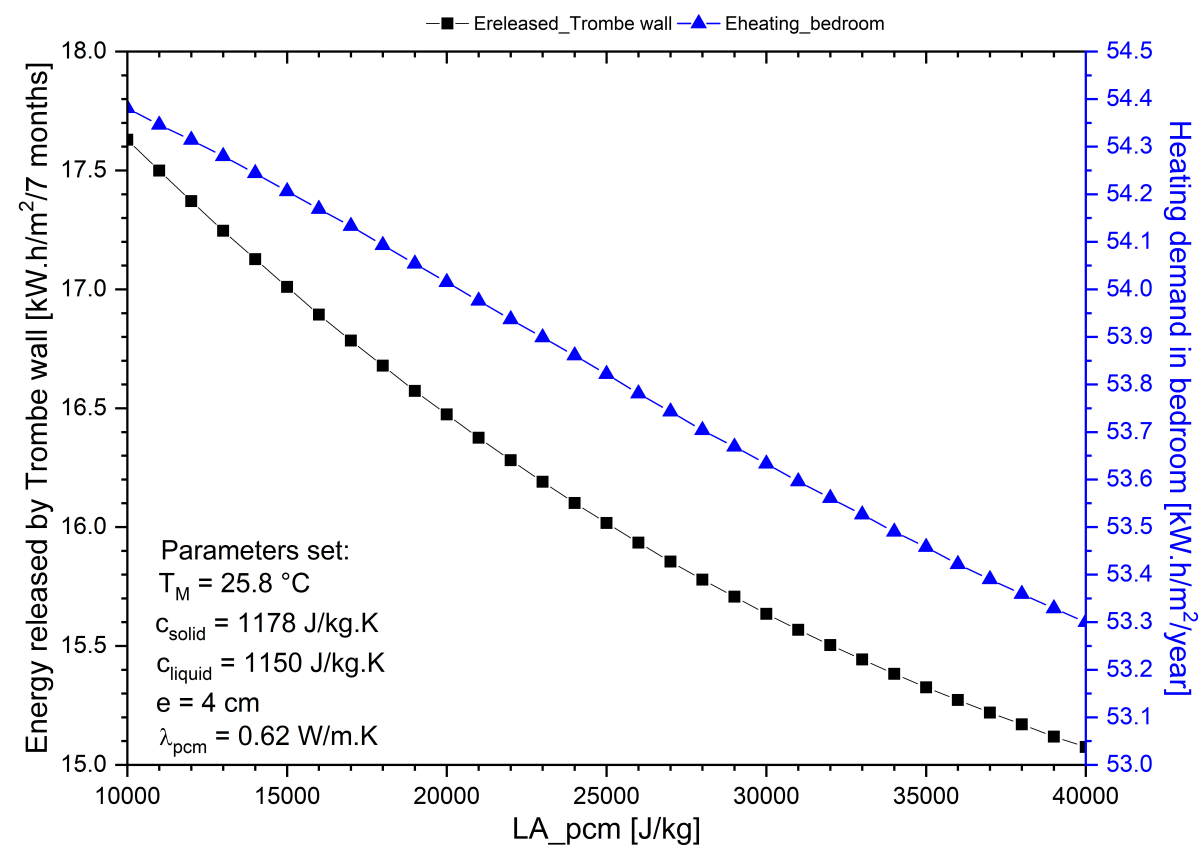

Figure 3. Energy supplied by the solar Trombe wall and annual heating demand vs. latent heat during the cold season (7 months total: January-April and October-December).

Figure 4 displays the fluctuation in power supplied and temperature inside the bedroom during two winter days relative to three latent heat values. For the first day, as the power supplied increases, the temperature curve lies above the setpoint temperature $\left(20^{\circ} \mathrm{C}\right)$. The lower the latent heat, the higher the overheating (roughly up to $26^{\circ} \mathrm{C}$ ). Additionally revealed is that when the temperature

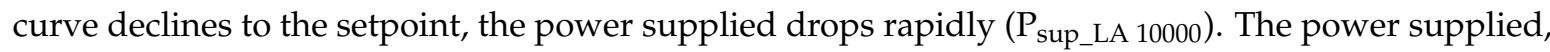
with higher latent heat, is greater, and its curve decreases slowly during the night. The total energy supplied and heating demand applied with the three latent heat values, as calculated by integrating power as a function of time, are given in Table 3.

Table 3. Energy supplied by the solar Trombe wall and heating demand over 2 days.

\begin{tabular}{ccc}
\hline LA $_{\mathbf{p c m}}(\mathbf{J} / \mathbf{k g})$ & E Supplied for $\mathbf{2}$ Whole Days & E Heating Demand for 2 Days \\
\hline 10,000 & $2.60 \mathrm{~kW} \cdot \mathrm{h}$ & $0.35 \mathrm{~kW} \cdot \mathrm{h}$ \\
25,000 & $2.26 \mathrm{~kW} \cdot \mathrm{h}$ & $0.52 \mathrm{~kW} \cdot \mathrm{h}$ \\
40,000 & $1.89 \mathrm{~kW} \cdot \mathrm{h}$ & $0.58 \mathrm{~kW} \cdot \mathrm{h}$ \\
\hline
\end{tabular}




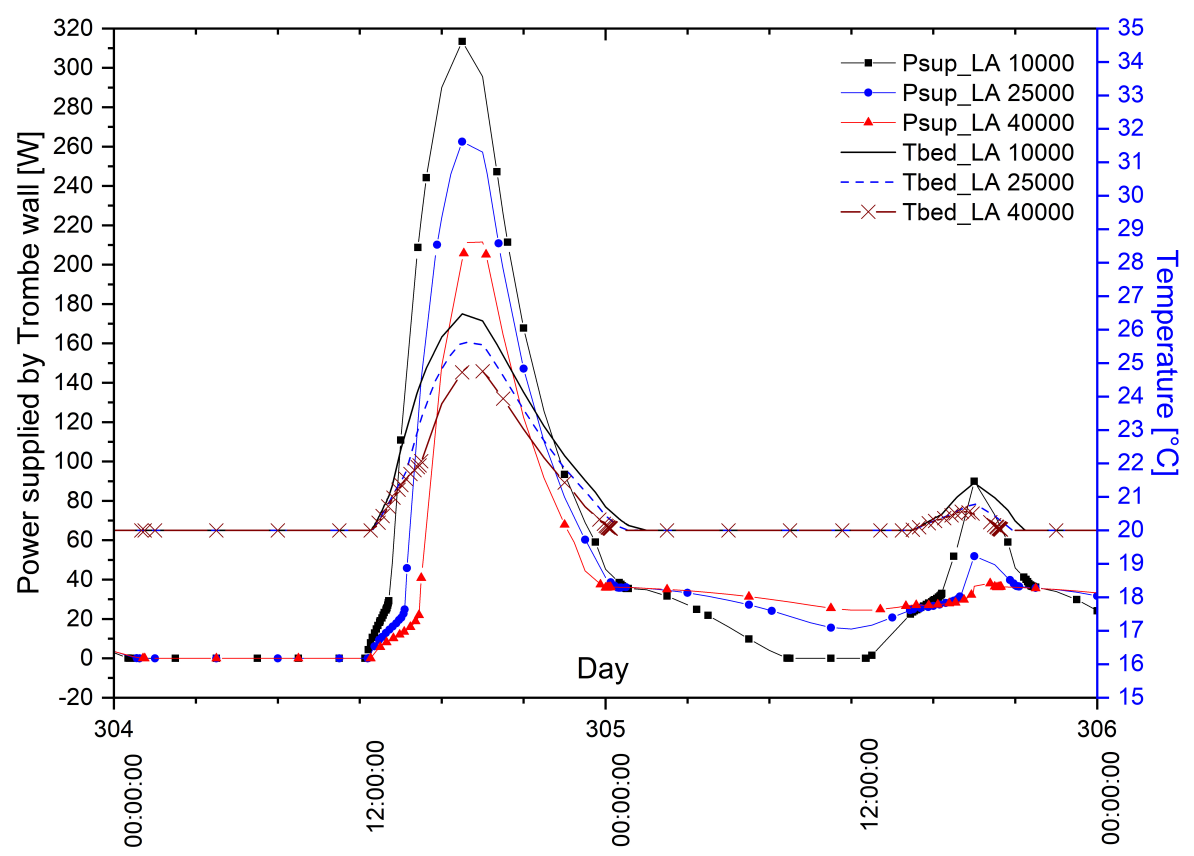

Figure 4. Effect of latent heat on the power released by the solar Trombe wall and temperature inside the bedroom.

The second column shows that for two days of integration, the lower the latent heat, the higher the energy supplied $(2.60 \mathrm{~kW} \cdot \mathrm{h}>1.89 \mathrm{~kW} \cdot \mathrm{h})$. In contrast, for the third column, instead of integration over two whole days, it is exclusively integrated when heating is required, meaning that the energy is calculated when temperature inside the bedroom is equal to the setpoint temperature of $20^{\circ} \mathrm{C}$. It can thus be noted that the higher the latent heat, the higher the energy heating demand $(0.58 \mathrm{~kW} \cdot \mathrm{h}>0.35 \mathrm{~kW} \cdot \mathrm{h})$. The solar Trombe wall with lower latent heat cannot sufficiently charge or discharge the thermal energy; it releases thermal heat to the bedroom at an inappropriate time (i.e., with energy from direct solar contributions), hence making energy needs for heating unnecessary and sometimes resulting in overheating.

\subsection{Variation in Melting Temperature (TM_pcm)}

Figure 5 presents the effect of PCM melting temperature from $18.8^{\circ} \mathrm{C}$ to $55.8^{\circ} \mathrm{C}$. The heating demand has an amplitude of approximately $2 \mathrm{kWh} \cdot \mathrm{m}^{-2} \cdot \mathrm{year}^{-1}$. An increase in melting temperature produces a variation in both the energy supplied and heating demand curves.

Figure 6 shows the thermal performance of the solar Trombe wall, as applied with four melting temperatures vs. power supplied, temperature inside the bedroom and temperature at the center of the PCM storage wall. The period of days 304 to 305 was chosen as this period enables the PCM storage wall to fully charge the solar gains and let the PCM go over the melting temperature.

It should be noted that the temperature at the center of the PCM storage wall varies over the first day; it evolves from $15{ }^{\circ} \mathrm{C}$ to roughly $55^{\circ} \mathrm{C}$. During the hot season, this amplitude can progress from $10^{\circ} \mathrm{C}$ to $80^{\circ} \mathrm{C}$, as reflected in Figure 7. Temperature fluctuations at the center of the PCM storage wall during the heating period highlight the benefit of choosing a melting temperature neither too low nor too high. Consequently, it can be stated that as the PCM melting temperature increases, the phase change occurs less frequently, resulting in increased heating demand. However, this situation presents the paradox compared to the previous case, as regards the decrease in latent heat increasing heating demand. This set-up also demonstrates that the lower the PCM melting temperature, the higher the heating demand $\left(\mathrm{TM}_{\mathrm{pcm}}\right.$ shifts from $30.8^{\circ} \mathrm{C}$ to $\left.20.8^{\circ} \mathrm{C}\right)$, which can be explained by the fact that over the period while the value of PCM melting temperature is too small, the PCM phase change 
is inappropriate to sufficiently charge thermal energy. According to the curve, the lowest heating demand corresponds to an optimal PCM melting temperature value of $30.8^{\circ} \mathrm{C}$.

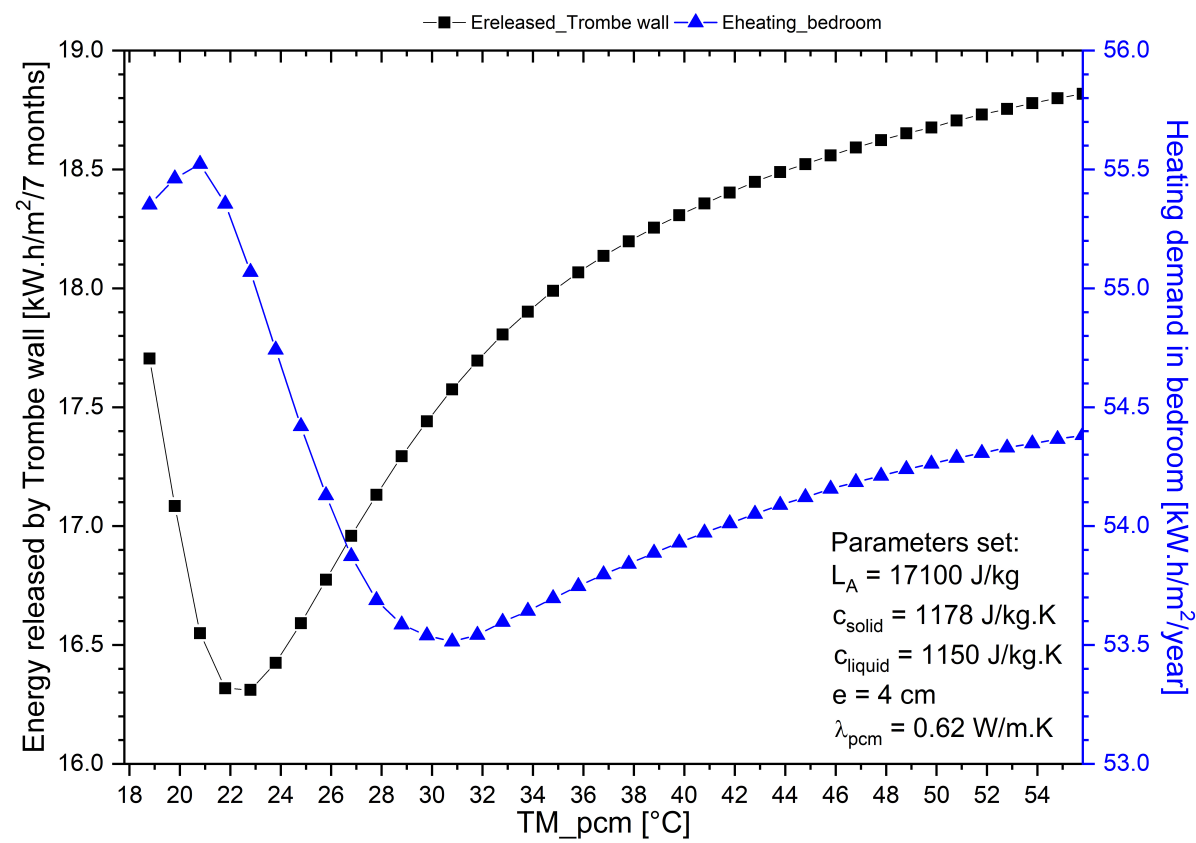

Figure 5. Energy released by the solar Trombe wall and heating demand in the bedroom vs. melting temperature during the cold season (7 months total: January-April and October-December).

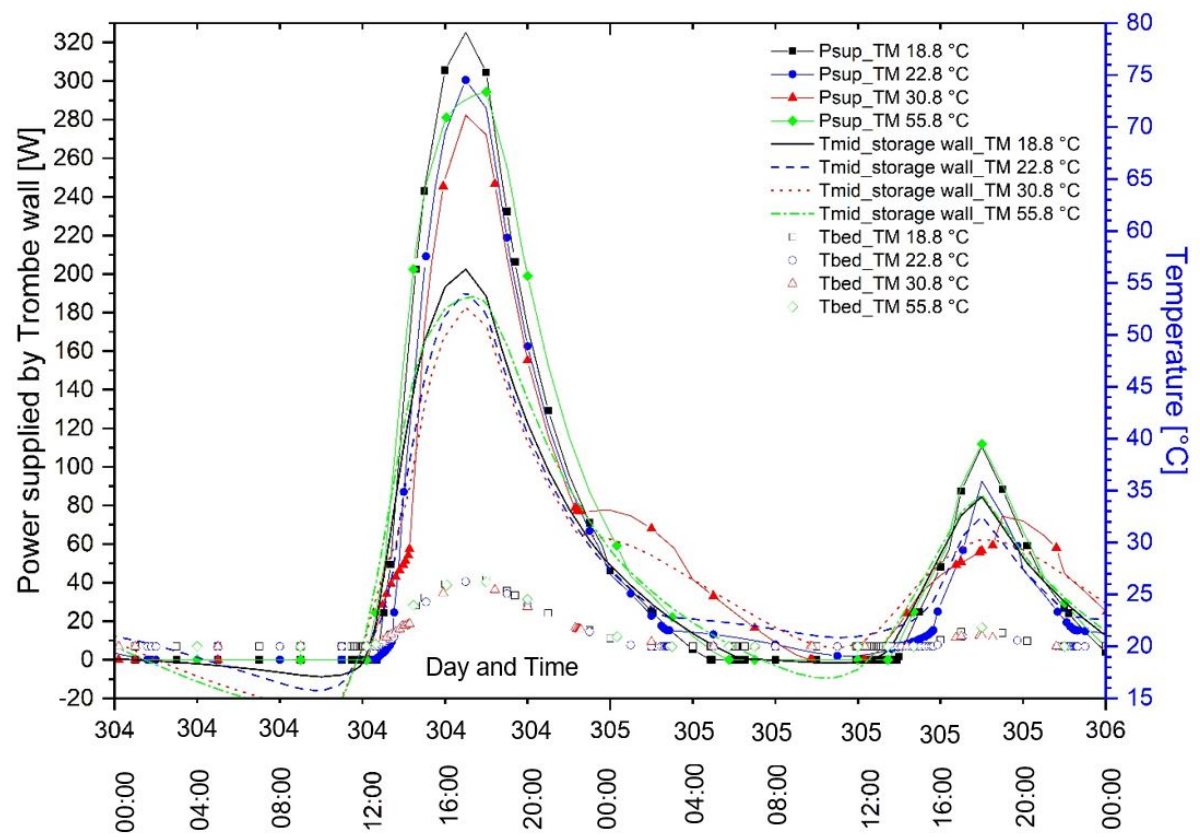

Figure 6. Variations in: the power supplied by the solar Trombe wall, temperature at the center of the phase change material (PCM) storage wall and temperature inside the bedroom. 

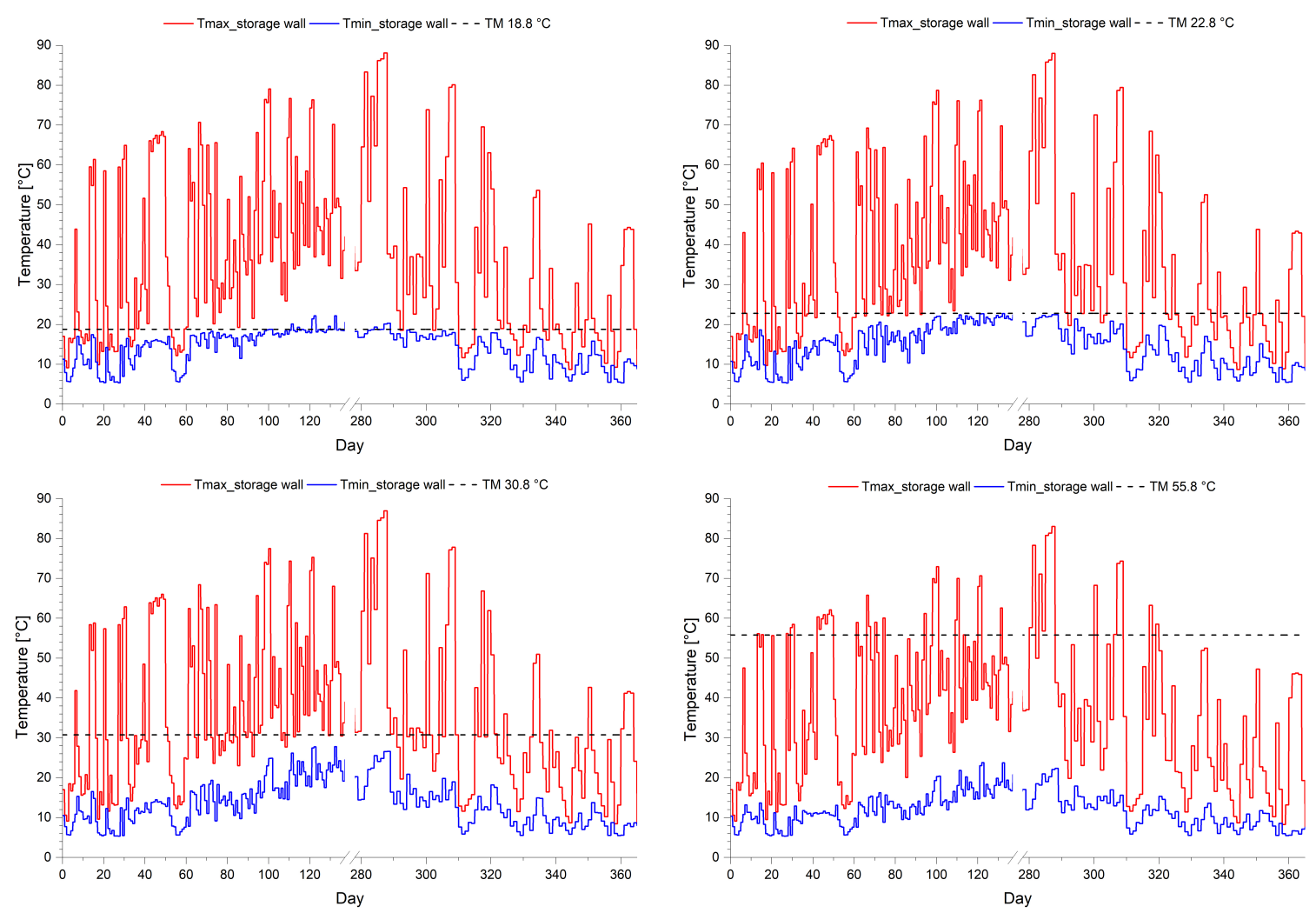

Figure 7. Daily amplitudes during the entire year of temperature fluctuations at the center of the PCM storage wall vs. four different values of PCM melting temperature. $\mathrm{T}_{\text {max_storage wall }}$ and $\mathrm{T}_{\text {min_storage wall }}$ denote respectively the daily maximum and minimum temperatures.

\subsection{Variation in the PCM Storage Wall Thickness (e_pcm)}

Figure 8 shows that the energy supplied decreases as the storage wall thickness increases from $4 \mathrm{~cm}$ to $15 \mathrm{~cm}$, whereas the heating demand curve begins to decline from $4 \mathrm{~cm}$ to $12 \mathrm{~cm}$ before increasing from $12 \mathrm{~cm}$ to $15 \mathrm{~cm}$. The approximate minimum value of the curve presenting heating demand remains within the range of $10 \mathrm{~cm}$ to $15 \mathrm{~cm}$, which is relatively flat and yields a difference of roughly $1.5 \mathrm{kWh} \cdot \mathrm{m}^{-2}$.year ${ }^{-1}$. Figure 9 provides the variation in power supplied as well as the temperature variation inside the bedroom for a 2-day simulation during early winter based on three values of storage wall thickness. This figure indicates that the $12-\mathrm{cm}$ thick storage wall charges and discharges power at the appropriate time.

These results show that the thinner the storage wall, the higher the energy supplied and the heating demand; it further demonstrates that the temperature inside a bedroom integrated with a thinner storage wall is increasing $\left(\mathrm{e}_{\mathrm{pcm}}=4 \mathrm{~cm}\right)$. The power supplied with a storage wall of $12 \mathrm{~cm}$ to $15 \mathrm{~cm}$ thick shows poorer results than a $4-\mathrm{cm}$ thick wall, while the temperature curves inside the bedroom containing a $12-\mathrm{cm}$ or $15-\mathrm{cm}$ thick storage wall are also below those of a $4-\mathrm{cm}$ thick wall. Similarly, for the variation of latent heat, it should be noted that the power supplied with a wall thickness of $4 \mathrm{~cm}$ decreases rapidly, while temperature inside the bedroom also decreases towards the setpoint temperature compared to the other configurations (i.e., curves of $T_{\text {bed_e } 12 \mathrm{~cm}}$ and $T_{\text {bed_e }} 15 \mathrm{~cm}$ ). Conversely, the power supplied remains positive longer than the case with the thinner wall (e.g., $4 \mathrm{~cm}$ ) at night when installing the thicker storage wall. Table 4 reports the total energy supplied and heating demand vs. three values of storage wall thickness. 


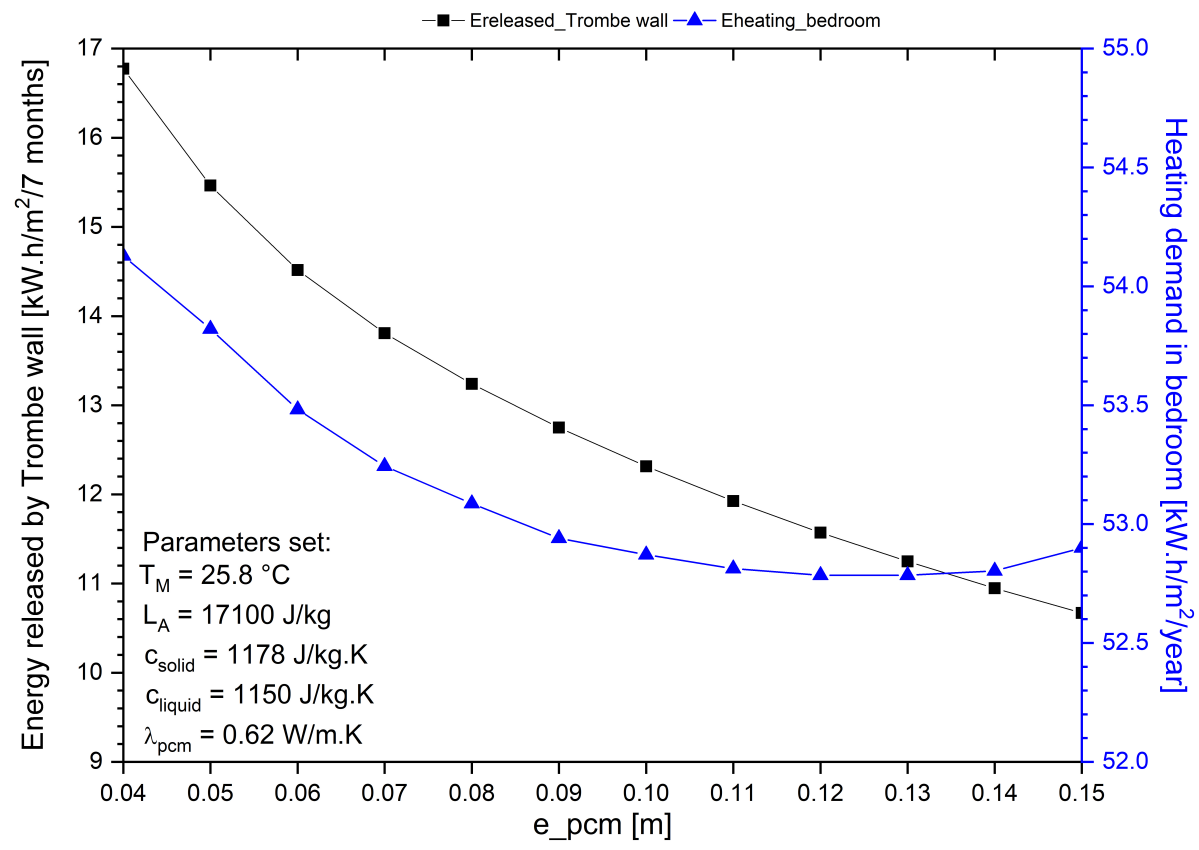

Figure 8. Energy released by the solar Trombe wall and heating demand vs. storage wall thickness during the cold season (7 months total: January-April and October-December).

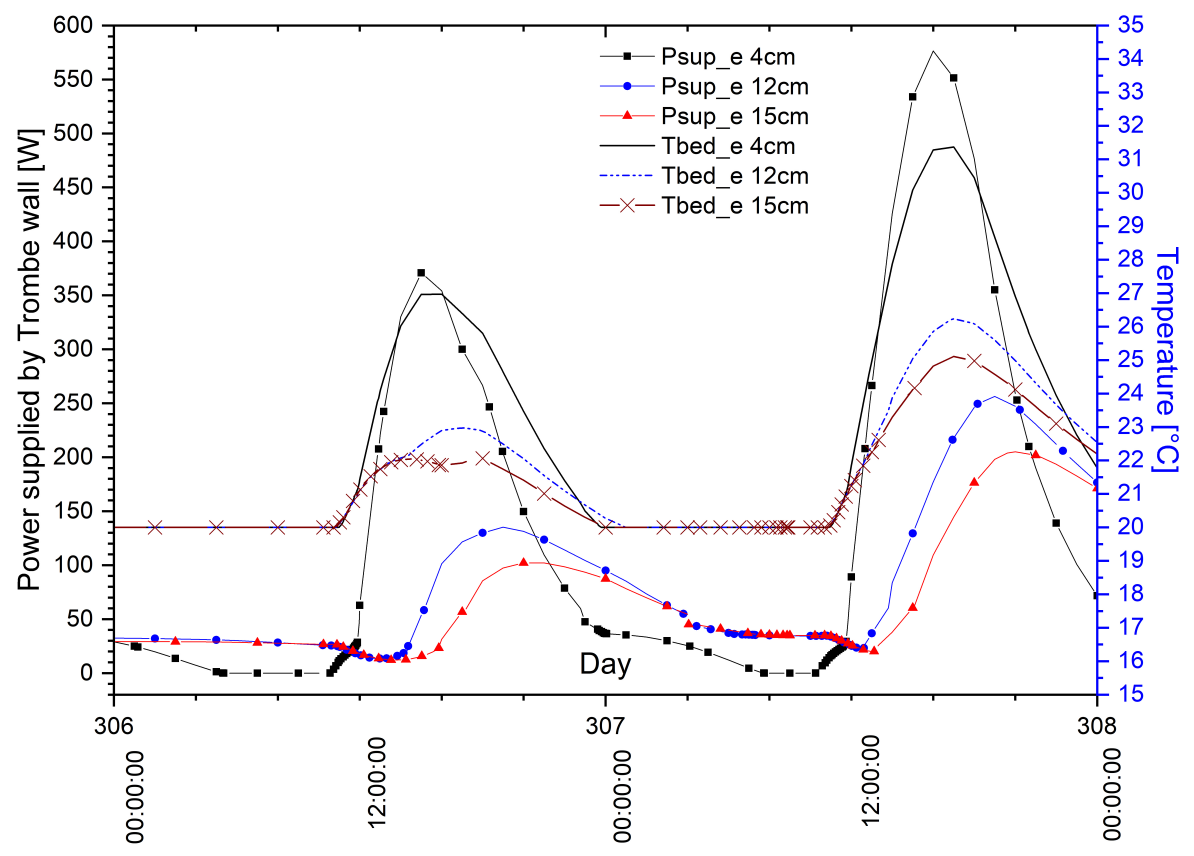

Figure 9. Effect of PCM storage wall thickness on the power released by the solar Trombe wall and temperature inside the bedroom.

Table 4. Energy supplied by the solar Trombe wall and energy heating demand.

\begin{tabular}{ccc}
\hline $\mathbf{e}_{\mathbf{p c m}}(\mathbf{m})$ & E Supplied for $\mathbf{2}$ Whole Days & E Heating Demand for 2 Days \\
\hline 4 & $6.791 \mathrm{~kW} \cdot \mathrm{h}$ & $0.282 \mathrm{~kW} \cdot \mathrm{h}$ \\
12 & $4.251 \mathrm{~kW} \cdot \mathrm{h}$ & $0.837 \mathrm{~kW} \cdot \mathrm{h}$ \\
15 & $3.393 \mathrm{~kW} \cdot \mathrm{h}$ & $0.818 \mathrm{~kW} \cdot \mathrm{h}$ \\
\hline
\end{tabular}

Nevertheless, these findings suggest that the optimal PCM storage wall is 12-cm thick, based on the result obtained from heating demand $(0.837 \mathrm{~kW} \cdot \mathrm{h})$ according to Table 4 as well as the heating 
demand curve in Figure 8. A 12-cm thickness is appropriate to charge and discharge whenever heating demand warrants.

\subsection{Variation in Thermal Conductivity ( $\left.\lambda \_p c m\right)$}

Figure 10 shows the effect of thermal conductivity on heating demand, which varies by $1 \mathrm{kWh} \cdot \mathrm{m}^{-2}$. year $^{-1}$; it further indicates that as thermal conductivity $\lambda_{\mathrm{pcm}}$ increases, the energy supplied by the solar Trombe wall also increases, even as heating demand decreases. Figure 11 presents the gain in power supplied and temperature inside the bedroom as thermal conductivity increases from $0.22 \mathrm{~W} / \mathrm{m} \cdot \mathrm{K}$ to $1.02 \mathrm{~W} / \mathrm{m} \cdot \mathrm{K}$.

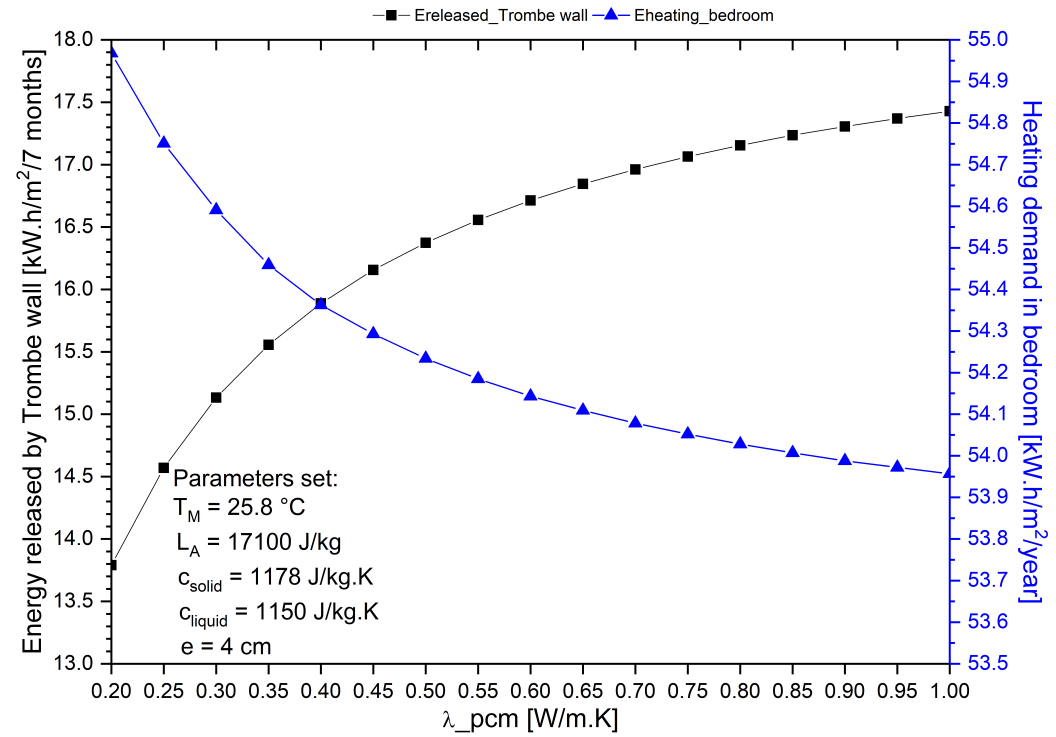

Figure 10. Energy released by the solar Trombe wall and heating demand vs. thermal conductivity during the cold season (7 months total: January-April and October-December).

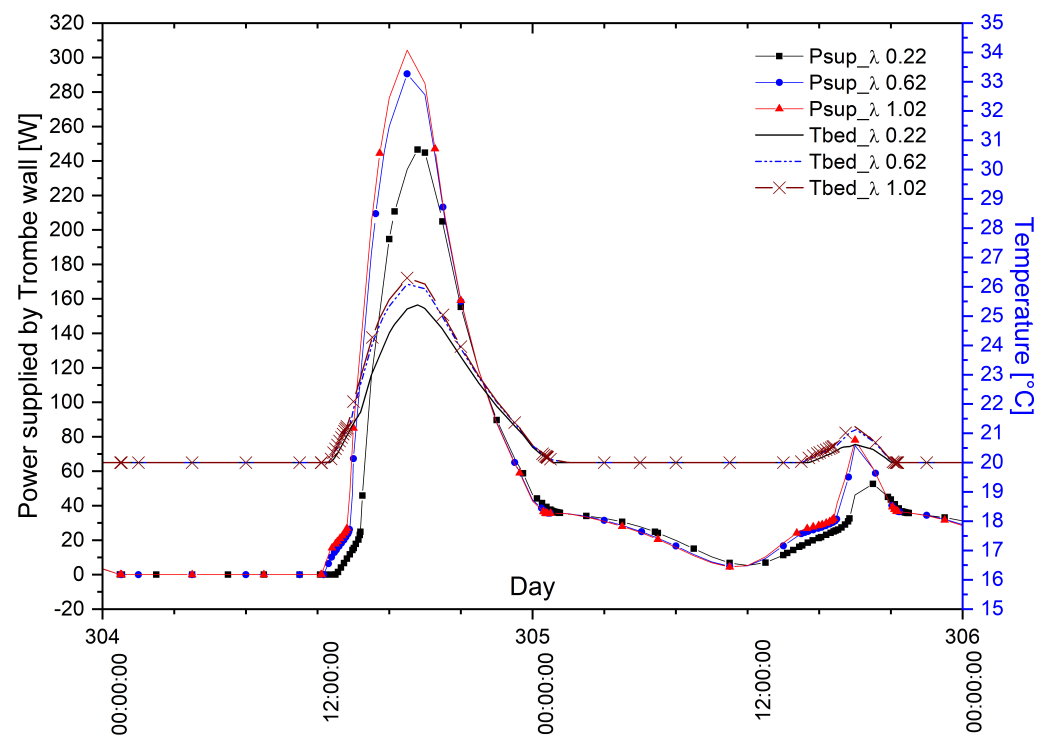

Figure 11. Effect of PCM thermal conductivity on both the power released by the solar Trombe wall and temperature inside the bedroom.

The variation in thermal conductivity only slightly impacts the difference in temperature and power supplied compared to the previous parameters studies $\left(\mathrm{LA}_{\mathrm{pcm}}, \mathrm{TM}_{\mathrm{pcm}}\right.$ and $\left.\lambda_{\mathrm{pcm}}\right)$. Nevertheless, 
it does substantially influence the amplitude of these variables since it favors the direct transfer of thermal energy and power supplied to the bedroom.

\section{Effect of Solar Wall Parameters on Building Comfort during Winter}

Let us note that comfort is studied herein only over the heating period because the solar wall is not used during the rest of the year. To assess thermal comfort in the building, the comfort observation criteria, relying on the notion of adaptive thermal comfort performance, will be applied (see related paper [50]). The defined value of thermal comfort has been provided in Section 2.5 of the previous study [24]. The variation ranges and parametric studies given in Table 2 are applied the same as above.

Figures 12-15 show the number of hours of thermal discomfort in the room according to each parameter. The variation in heating demand presented in the preceding sections has been included herein. In the basic simulation, the number of hours of discomfort (number of hours when the temperature exceeds the comfort setpoint $+3.5^{\circ} \mathrm{C}$ ) was 220 over the entire heating period.

Figure 12 shows that the increase in latent heat over the studied range results in minimizing the number of hours by approximately 40 . Furthermore, this figure informs that depending on the curve presenting temperature fluctuation inside the bedroom (given in Figure 4), the higher the latent heat, the lower the temperature peaks observed in the bedroom, as reflected in the decrease in the number of hours of thermal discomfort.

Regarding the melting temperature, Figure 13, this parameter also minimizes the number of hours of discomfort by roughly $40 \mathrm{~h}$. However, its optimal temperature equals about $44^{\circ} \mathrm{C}$, while the minimal heating demand corresponds to an optimal melting temperature value of around $32{ }^{\circ} \mathrm{C}$. It is also shown that between $35{ }^{\circ} \mathrm{C}$ and $52{ }^{\circ} \mathrm{C}$, the variation in the number of hours remains quite flat. Whether at a low or high PCM melting temperature, the optimal heating demand does not provide a minimum value, due to the fact that phase change within the storage wall is of an insufficient magnitude for the high PCM melting temperature, and the process of charging and discharging thermal heat takes place within too short a time for the low PCM melting temperature (Figure 6).

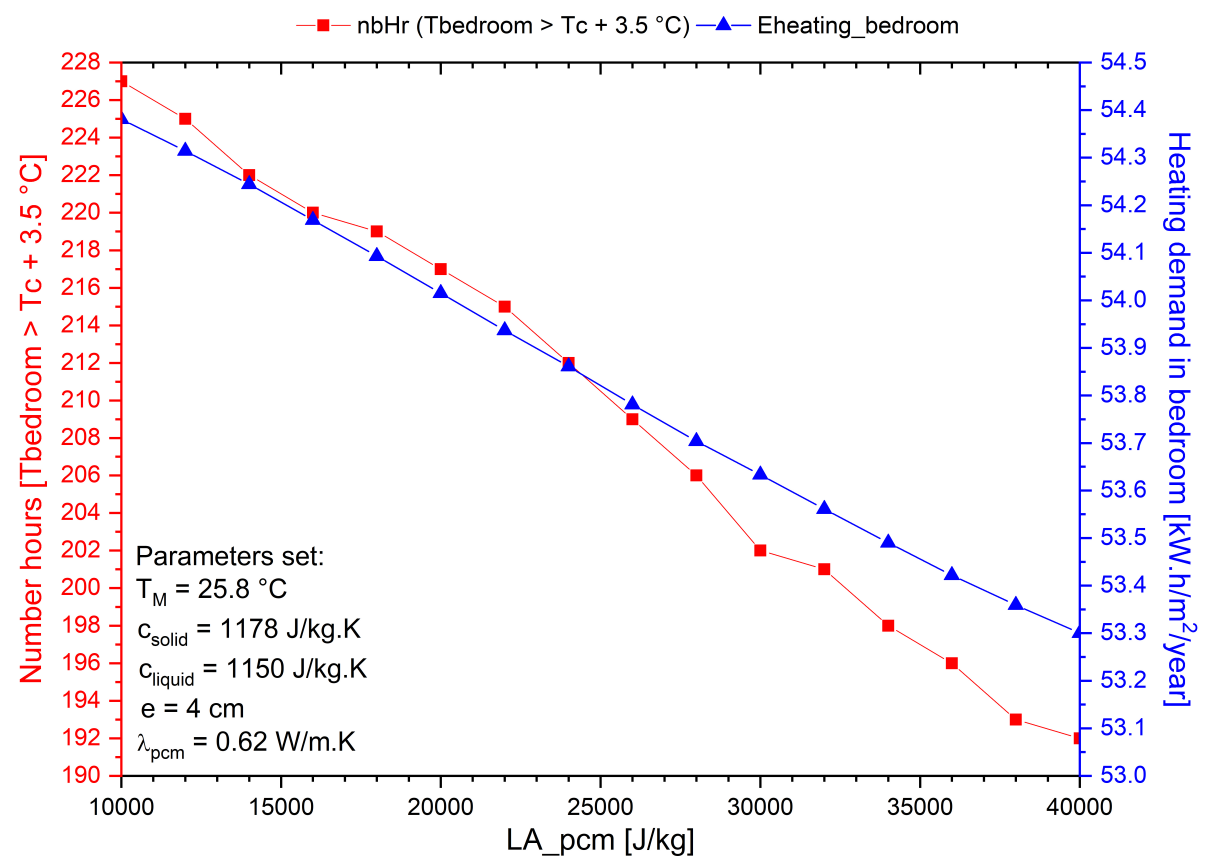

Figure 12. Number of hours of thermal discomfort and heating demand vs. latent heat during the cold season (7 months total: January-April and October-December). 


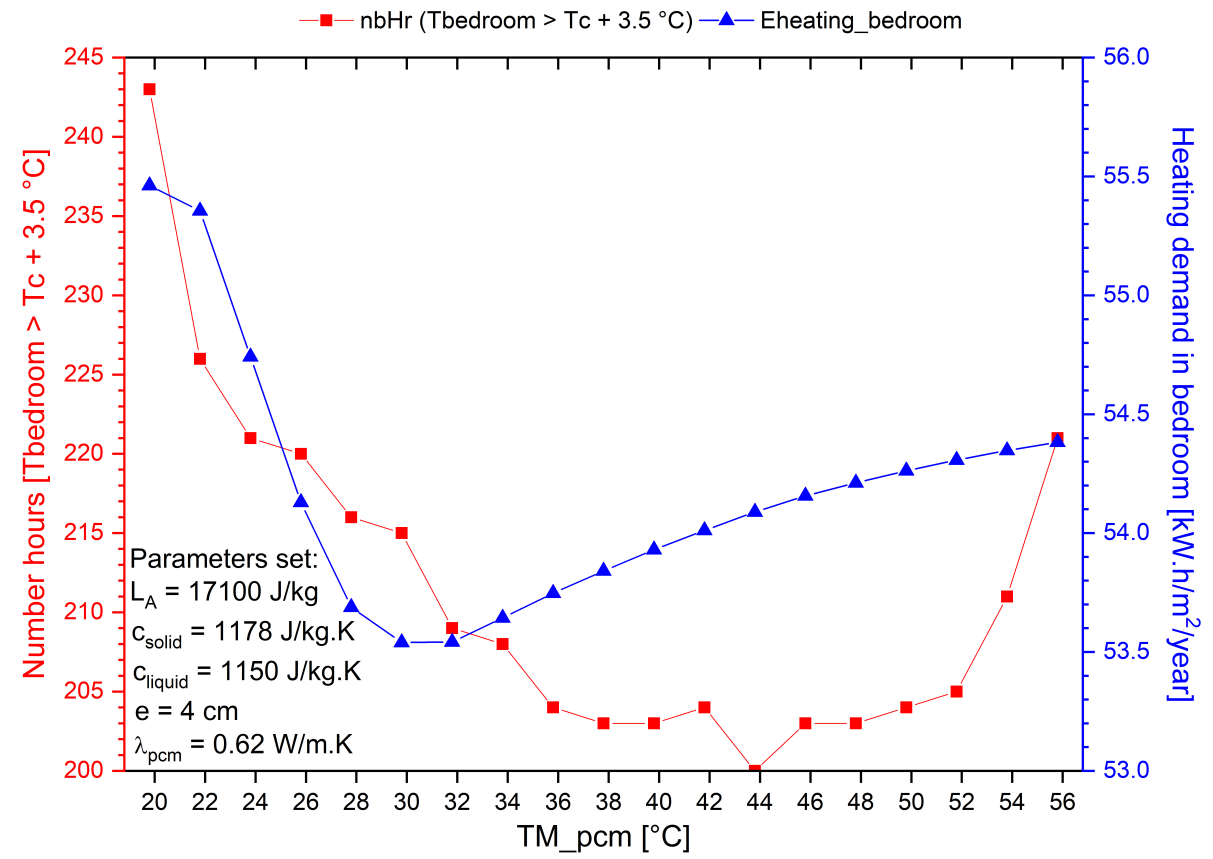

Figure 13. Number of hours of thermal discomfort and heating demand vs. melting temperature during the cold season (7 months total: January-April and October-December).

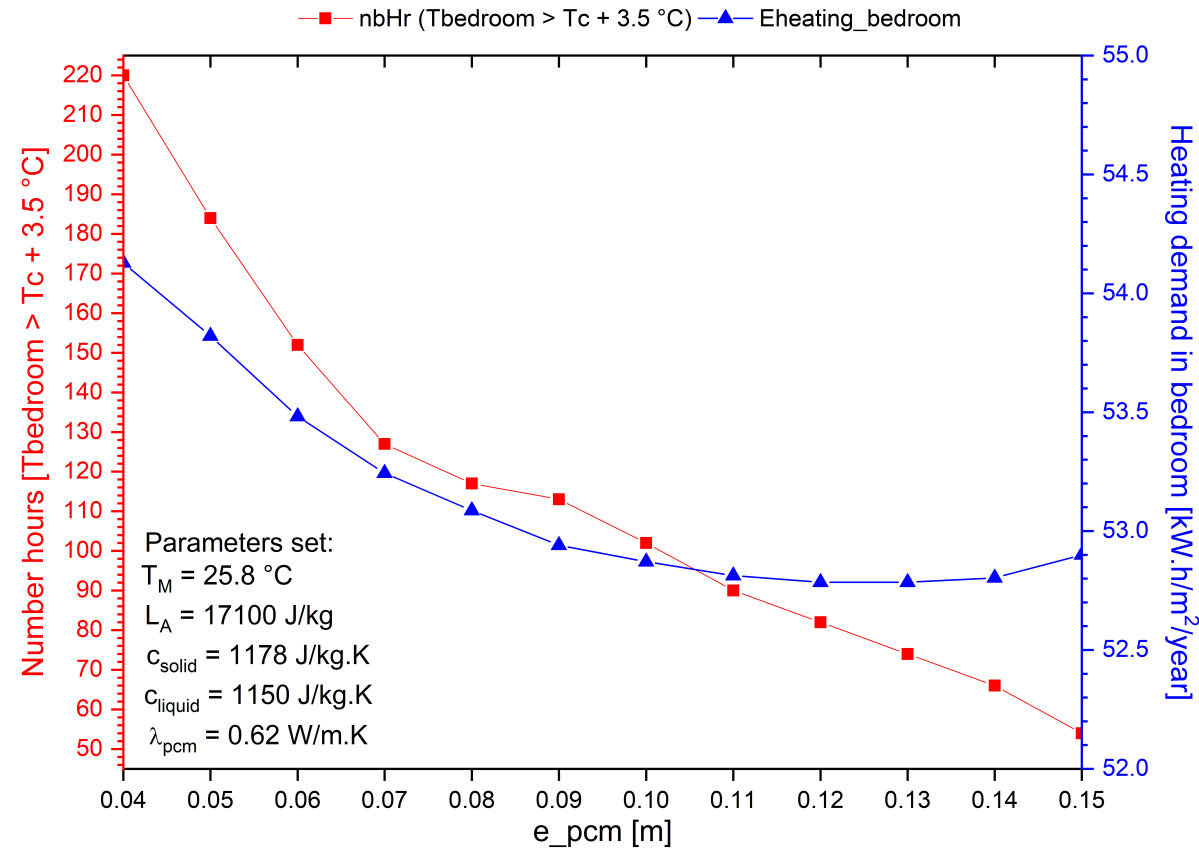

Figure 14. Number of hours of thermal discomfort and heating demand vs. storage wall thickness during the cold season (7 months total: January-April and October-December). 


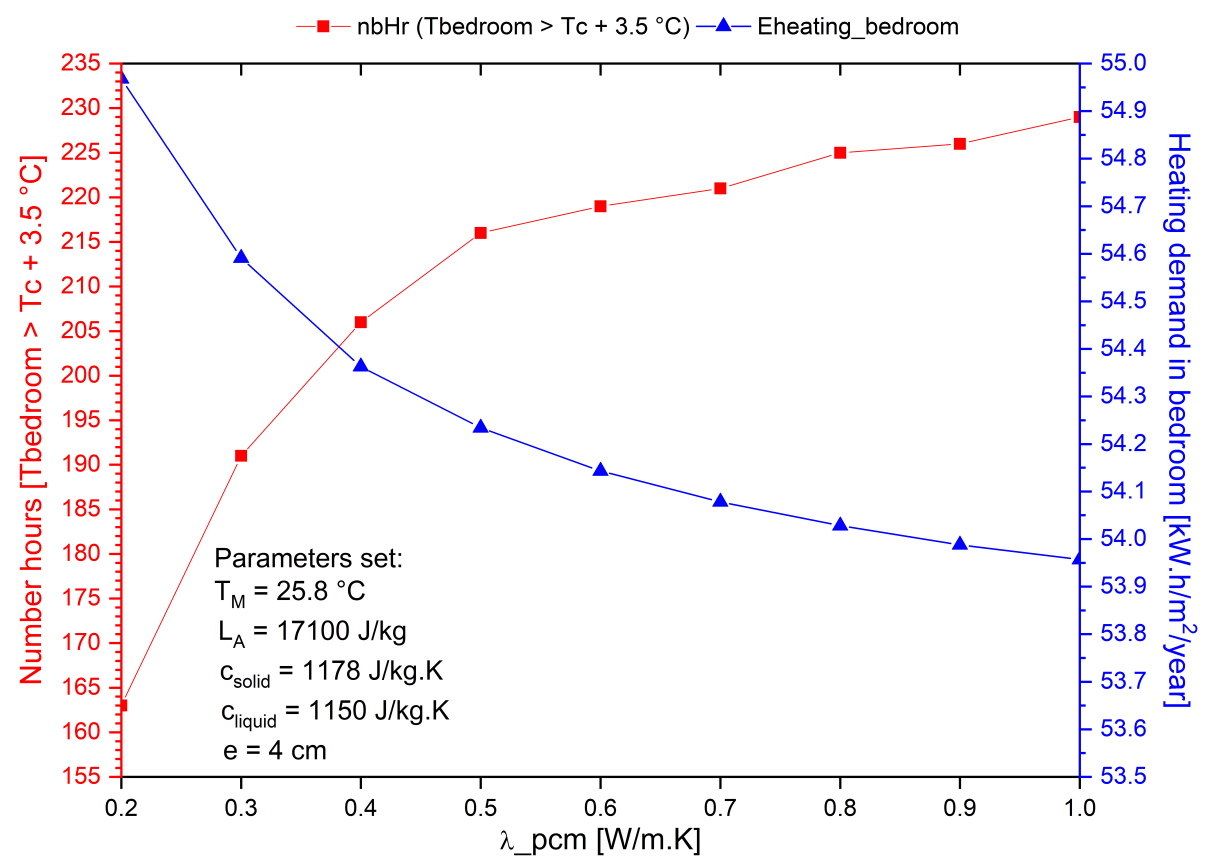

Figure 15. Number of hours of thermal discomfort and heating demand vs. thermal conductivity during the cold season (7 months total: January-April and Octobr-December).

For this application, the storage wall thickness seems to be the most effective parameter within the defined ranges, Figure 14. PCM storage wall thickness, with an increase from $4 \mathrm{~cm}$ to $15 \mathrm{~cm}$, allows reducing the number of hours of discomfort from 220 to 50 . This reduces the time of discomfort from $5 \%$ of the time to less than 1\%, which is acceptable as stated by Stazi et al. [51] referring to Method A-AnnexF-ISO EN 15251.

The thicker the PCM storage wall, the smaller the number of hours of discomfort. This result is consistent with that illustrated in Figure 9, i.e., as the PCM storage wall thickens, the solar gain is diminished and causes a lower temperature in the bedroom.

Moreover, the PCM thermal conductivity over the defined range raises the number of hours of discomfort from 163 to 229, Figure 15. Hence, the higher the thermal conductivity, the greater the number of hours of thermal discomfort. Indeed, as thermal conductivity increases, heat transfer is favored over storage. Therefore, given the apparent inertia of the PCM storage wall, thermal energy transfers simultaneously with direct solar contributions, making for a quick onset of discomfort.

\section{Optimization Process Methodology}

The parametric study presented above does not yield the set of parameters providing the minimum heating demand or the best comfort inside the bedroom since each parameter is optimized by holding the others fixed. Therefore, the simulation-based optimization method described in this section will be used to optimize the designed house model by coupling all four parameters as the variable input setting in GenOpt, whereby a defined objective function will serve as a global study of the perimeter and no longer the parametric optimization, which is a local study.

\subsection{Optimization Method}

For this purpose, a generic optimization ('GenOpt') tool is employed to minimize the objective function, in denoting respectively: the heating demand objective function, the number of hours of discomfort objective function and the single-objective function. The optimization method utilized is a nonlinear descent method, called "Generalized Pattern Search" with multiple initial points, thus making it possible to process the optimization of both nonlinear and non-continuous systems. 
After the first optimization, for which the initial parameters are fixed, several other initial values for the parameters are randomly chosen in order to avoid local minima (Figure 16).

Here, three optimizations are performed independently, namely:

1. Optimization of heating demand;

2. optimization of the number of hours of thermal discomfort;

3. simultaneous optimization of heating demand and number of hours of discomfort.

\subsection{Optimization of Heating Demand}

To reduce computation time, heating demand over the first 4 months of the year will serve as an objective function. Note that the optimal results of heating demand energy for the whole year tested with a single initial point (again to reduce computation time) are the same as those over 7 months. Moreover, it is observed that the optimization over the last 3 months of the year produces similar results. Figure 16 and Table 5 show the optimization results for Paris weather, beginning with the first initial value and then two more with initial values chosen and run randomly by GenOpt; the final optimization results are identical. The latent heat and thermal conductivity parameters reach the upper bound of the defined range, meaning that the set parameters identified here are dependent on method parameterization.

It can therefore be noted that the optimal values of latent heat and thermal conductivity are obtained in the certain absence of an optimum (physically realistic). additionally shown is that the higher the latent heat and thermal conductivity, the lower the heating demand. The same results are found here as in the parametric study. On the other hand, the optimal values of $9 \mathrm{~cm}$ thick and $31.5^{\circ} \mathrm{C}$ for PCM thickness and melting temperature are found to lie within the defined range. The melting temperature found from the optimized heating demand objective function is the same as that derived in the parametric study.

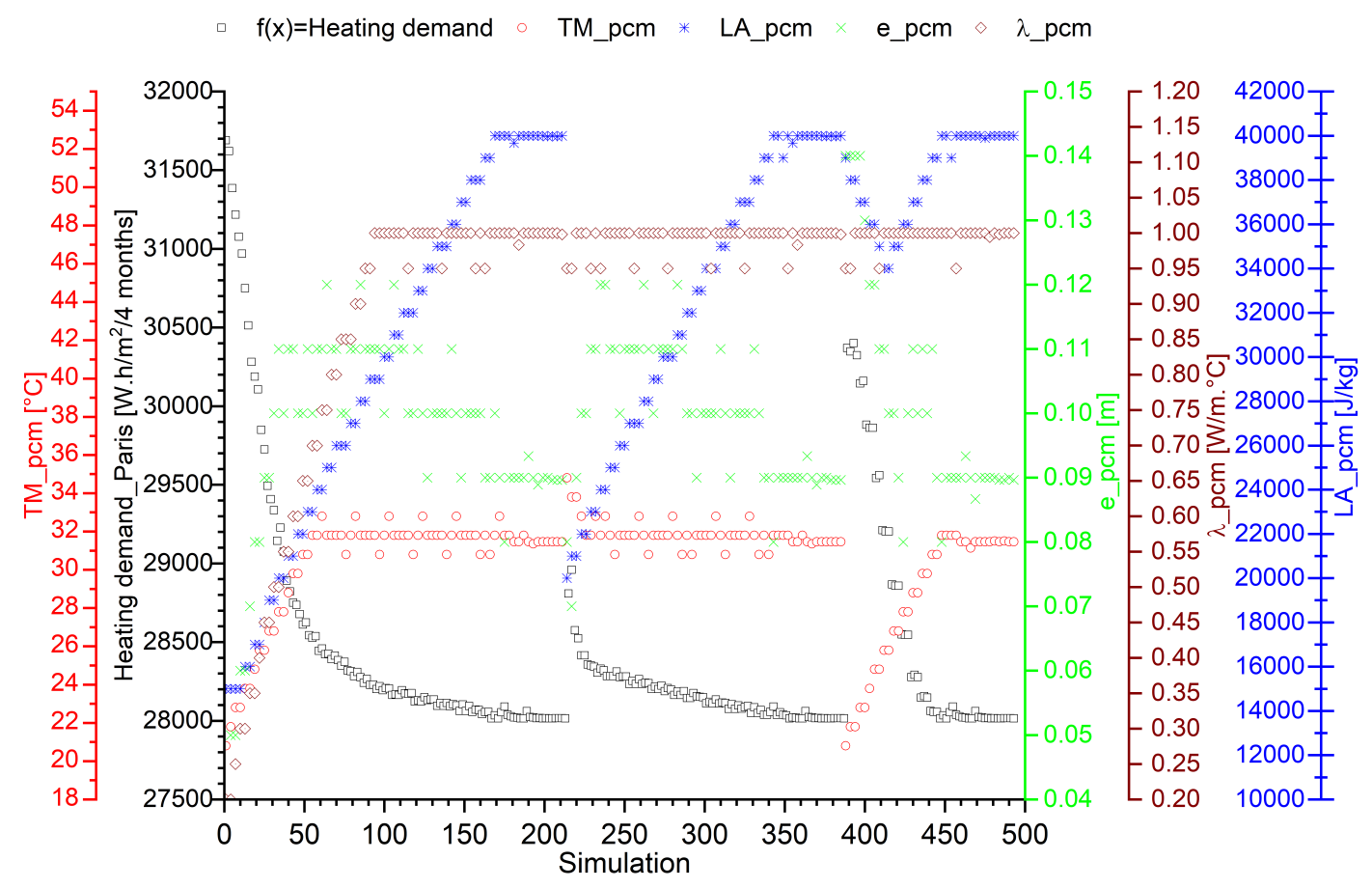

Figure 16. Variation in the objective function $(\mathrm{f}(\mathrm{x})=$ Heating demand), as subsequently simulated using three initial values. 
Table 5. Heating demand for four months of Paris weather based on three initial PCM parameter values.

\begin{tabular}{ccccccc}
\hline $\begin{array}{c}\text { Calculation } \\
\text { Number }\end{array}$ & & $\begin{array}{c}\mathbf{T M}_{\mathbf{p c m}} \\
{ }^{\circ} \mathrm{C}\end{array}$ & $\begin{array}{c}\mathbf{L A} \mathbf{p c m} \\
\mathbf{J} / \mathbf{k g}\end{array}$ & $\begin{array}{c}\mathbf{e}_{\mathbf{p c m}} \\
\mathbf{c m}\end{array}$ & $\begin{array}{c}\lambda_{\mathbf{p c m}} \\
\mathbf{W} / \mathbf{m} \cdot \mathbf{K}\end{array}$ & $\begin{array}{c}\text { Heating Demand } \\
\mathbf{k W h} \cdot \mathbf{m}^{-2} \cdot \mathbf{4} \mathbf{~ m o n t h s ~}^{-1}\end{array}$ \\
\hline \multirow{2}{*}{1} & Initial value & 20.8 & 15,000 & 4 & 0.22 & 31.69 \\
& Optimal value & 31.5 & $40,000^{*}$ & 9 & $1^{*}$ & 28.02 \\
2 & Initial value & 34.8 & 20,000 & 8 & 0.95 & 28.88 \\
\multirow{2}{*}{3} & Optimal value & 31.5 & $40,000^{*}$ & 9 & $1^{*}$ & 28.02 \\
& Initial value & 20.8 & 39,000 & 14 & 0.95 & 30.47 \\
& Optimal value & 31.5 & $40,000^{*}$ & 9 & $1^{*}$ & 28.02 \\
\hline
\end{tabular}

*: The upper bound has been reached for this parameter.

Table 6 reports the optimal parameters for three weather datasets; it indicates that the hotter the climatic zone, the higher the melting temperature and storage wall thickness.

Table 6. Optimal parameters of three distinct weather conditions (optimization of the heating demand objective function).

\begin{tabular}{cccccc}
\hline Weather & $\begin{array}{c}\mathbf{T M}_{\mathbf{p c m}} \\
{ }^{\circ} \mathbf{C}\end{array}$ & $\begin{array}{c}\mathbf{L A} \\
\mathbf{J} / \mathbf{k g}\end{array}$ & $\begin{array}{c}\mathbf{e}_{\mathbf{p c m}} \\
\mathbf{~ c m}\end{array}$ & $\begin{array}{c}\lambda_{\mathbf{p c m}} \\
\mathbf{W} / \mathbf{m} \cdot \mathbf{K}\end{array}$ & $\begin{array}{c}\text { Heating Demand } \\
\mathbf{k W h} \cdot \mathbf{m}^{-2} \cdot \mathbf{4} \mathbf{m o n t h s}^{-1}\end{array}$ \\
\hline Paris & 31.5 & $40,000 *$ & 9.0 & $1.00 *$ & 28.02 \\
Lyon & 32.9 & $40,000 *$ & 10 & $1,00 *$ & 24.10 \\
Nice & 32.8 & $40,000 *$ & 15 & $1.00 *$ & 2.23 \\
\hline
\end{tabular}

* The upper bound has been reached for this parameter.

Table 7 reports, for the full-year simulation, a comparison of the number of hours of thermal discomfort, the energy supplied by the solar Trombe wall during the cold season and heating demand relative to three configurations, i.e., the house without a solar Trombe wall, the house with a solar Trombe wall installed using both optimized and non-optimized PCM. These results reveal that the heating demand and number of hours of discomfort with the optimized incorporated PCM are reduced by: $5.2 \%\left(2.76 \mathrm{kWh} \cdot \mathrm{m}^{-2} \cdot\right.$ year $\left.^{-1}\right)$ and $86 \mathrm{~h}$ for Paris weather, $5.2 \%\left(2.53 \mathrm{kWh} \cdot \mathrm{m}^{-2} \cdot \mathrm{year}^{-1}\right)$ and $212 \mathrm{~h}$ for Lyon weather and $50 \%\left(4.35 \mathrm{kWh} \cdot \mathrm{m}^{-2} \cdot \mathrm{year}^{-1}\right)$ and $535 \mathrm{~h}$ for Nice weather, compared to the wall containing non-optimized PCM. As for the various results of energy supplied by the solar Trombe wall integrated with optimized and non-optimized PCM: $0.28 \mathrm{kWh} \cdot \mathrm{m}^{-2} \cdot \mathrm{year}^{-1}$ for Paris weather, $3.7 \mathrm{kWh} \cdot \mathrm{m}^{-2} \cdot$ year $^{-1}$ for Lyon weather and $5.8 \mathrm{kWh} \cdot \mathrm{m}^{-2} \cdot$ year $^{-1}$ for Nice weather.

Table 7. Number of hours of thermal discomfort, energy supplied and heating demand.

\begin{tabular}{|c|c|c|c|c|}
\hline \multirow[t]{2}{*}{ Paris-Orly } & non-optimized PCM & 170 & 18.68 & 53.42 \\
\hline & optimized PCM & 84 & 18.96 & 50.66 \\
\hline Lyon & optimized PCM & 150 & 23.03 & 46.46 \\
\hline \multirow{3}{*}{ Nice } & no Trombe wall & 0 & - & 21.07 \\
\hline & non-optimized PCM & 1,031 & 50.50 & 8.64 \\
\hline & optimized PCM & 496 & 44.70 & 4.29 \\
\hline
\end{tabular}

Qingsong M. et al. [42] had found an energy savings of the same order of magnitude (3.7\%) in their study "Optimizing energy performance of a ventilated composite Trombe wall in an office building" for the climate of Kitakyushu in Japan. In a study of the thermal impact of Trombe wall system for residential building in Mediterranean region, Jaber et al. [27] came to the conclusion that a Trombe wall with $18 \%$ of the south facade area can supply near $20.9 \%$ of the total heating needs. This 
result is lower than ours obtained in Nice (south of France: Mediterranean region), but the latter did not include PCM.

Figure 17 displays a comparison of temperature curves inside the bedroom for each of the three configurations. Figure 18 depicts the power supplied by the solar Trombe wall when applied with optimized and non-optimized PCM.

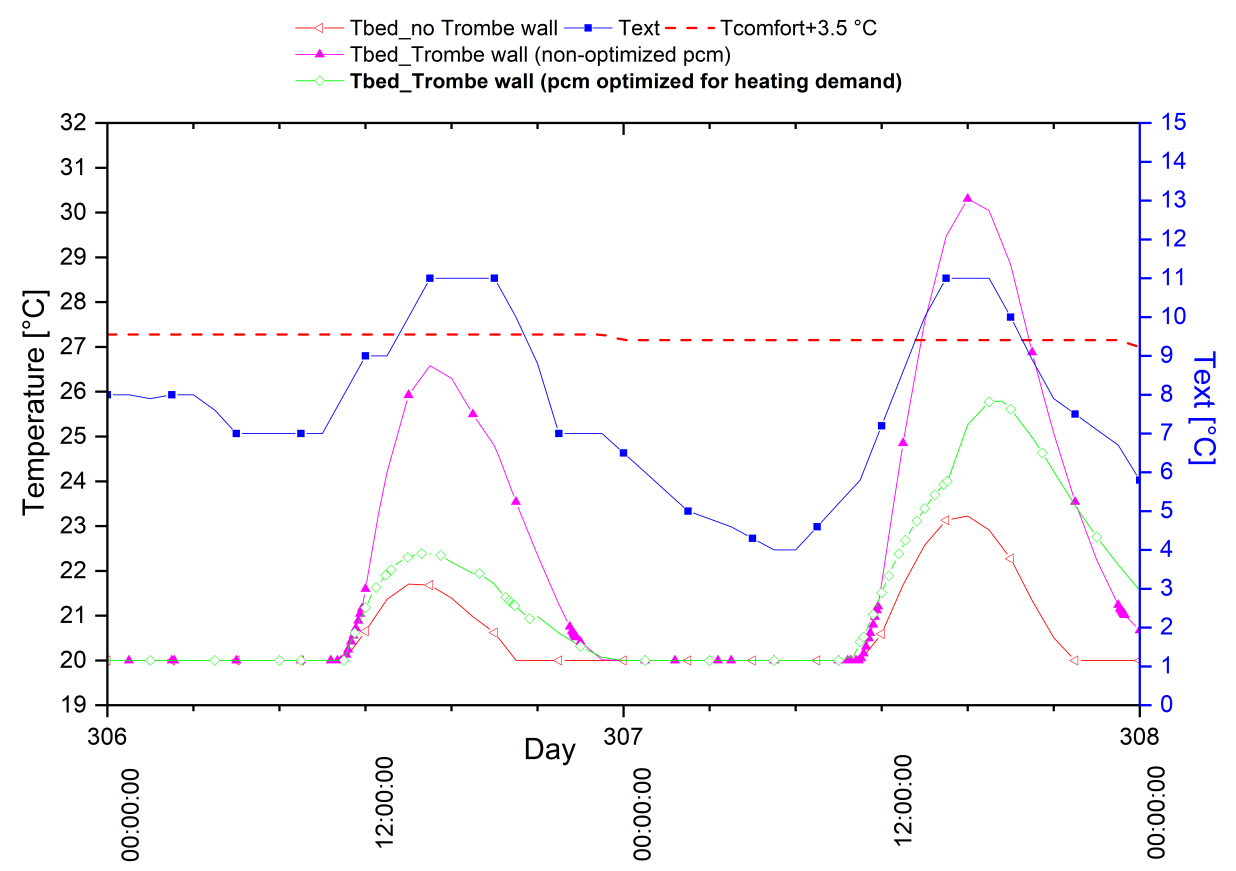

Figure 17. Temperature variations inside the bedroom. $\mathrm{T}_{\text {ext }}$ and $\mathrm{T}_{\text {comfort }+3.5^{\circ} \mathrm{C}}$ denote respectively the outside air temperature and comfort setpoint temperature plus $3.5^{\circ} \mathrm{C}$.

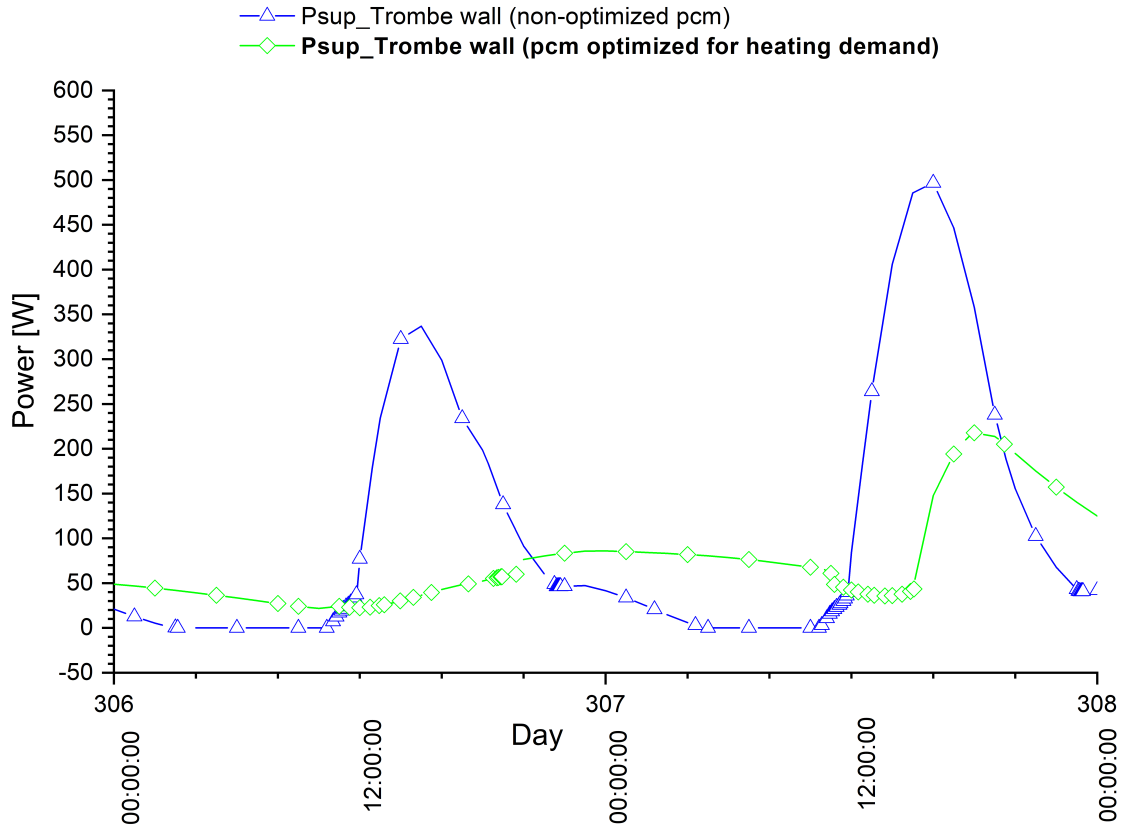

Figure 18. Comparison of the power supplied by the solar Trombe wall.

Regarding the obtained results of the optimization of heating demand, one can summarize that the PCM latent heat, melting temperature and thermal conductivity correlate with the parametric study given in Section 4; it is independent for the storage wall thickness $(9-\mathrm{cm}$ thick from the heating 
demand objective function, and 12-cm from the parametric study). The obtained results from the optimum values of PCM parameters for the full-year simulation show the reduction of the energy heating demands and number of hours of discomfort (Figure 17), and the higher power supplied by the solar wall during the heating demand (Figure 18).

\subsection{Optimization of the Number of Hours of Thermal Discomfort}

The optimization approach herein entails minimizing the number of hours of thermal discomfort objective function; its simulation will cover the same four months as the optimization of the heating demand objective function.

Table 8 reports the optimal results of those PCM parameters set up as independent variables in the objective function. According to the minimum number of hours of discomfort, the latent heat parameter reaches its upper bound for Paris weather, whereas it merely reaches the near upper bound for both Lyon and Nice weather conditions. This possibly exposes an optimization algorithm failure. Once the running algorithm reaches an optimum, it will test on both sides of its value. For instance, the optimized parameter is found at $40,000 \mathrm{~J} / \mathrm{kg}$; testing is then performed on a lower value, resulting in a decrease in the objective function. To clarify this point, the thermal building simulation tool Dymola/Modelica is used to simulate the parametric study of latent heat with other parameters constant, to trace the curve of the number of hours of discomfort (see Figure 19). This curve illustrates that the higher the latent heat, the lower the number of hours of discomfort; it further shows a slightly higher number of hours compared to that for $\mathrm{LA}_{\mathrm{pcm}}=40,000 \mathrm{~J} / \mathrm{kg}$. For those cases denoted "**", the upper bound has therefore been reached.

The number of hours of discomfort reaches zero for Paris weather; it is thus likely that the parameters identified are not the only ones to yield this result; an infinite number of solutions certainly exists. Moreover, the optimal parameters of PCM latent heat and storage wall thickness do reach the upper bound of their defined range; consequently, they cannot be confirmed as optimal parameters.

Table 8 reports that the increase in PCM latent heat can enhance thermal comfort inside the bedroom, while simultaneously reducing heating demand (see Section 6.2). Similarly, the optimal thickness reaches the upper bound of its defined range, although such is not the case when optimizing heating demand. According to the parametric studies of PCM thickness displayed in Figure 14, it can be observed that the minimum heating demand does not correspond to the upper bound of $\mathrm{e}_{\mathrm{pcm}}=15 \mathrm{~cm}$ in the defined range. The optimal values of thermal conductivity and melting temperature do lie within the defined range. Just like the results obtained from the heating demand objective function, the optimal melting temperature from the number of hours of discomfort objective function shows an increase in value relative to weather, i.e., the warmer the climate, the higher the melting temperature $\left(32.8^{\circ} \mathrm{C}\right.$ for Paris vs. $35.9^{\circ} \mathrm{C}$ for Nice).

Table 8. Optimal parameters for the three weather conditions (optimization of the number of hours of discomfort objective function).

\begin{tabular}{ccccccc}
\hline Weather & $\begin{array}{c}\mathbf{T M}_{\mathbf{p c m}} \\
{ }^{\circ} \mathbf{C}\end{array}$ & $\begin{array}{c}\mathbf{L A} \mathbf{p c m} \\
\mathbf{J} / \mathbf{k g}\end{array}$ & $\begin{array}{c}\mathbf{e}_{\mathbf{p c m}} \mathbf{c m} \\
\mathbf{\mathbf { W }} / \mathbf{m} \cdot \mathbf{K}\end{array}$ & $\begin{array}{c}\lambda_{\mathbf{p c m}} \\
\mathbf{k W h} \cdot \mathbf{m}^{-2} \cdot \mathbf{4} \mathbf{M o n t h s}^{-1}\end{array}$ & $\begin{array}{c}\text { No. of Hours of Discomfort } \\
\mathbf{h} / \mathbf{4} \text { Months }\end{array}$ \\
\hline Paris & 32.8 & $40,000^{*}$ & $15^{*}$ & 0.4 & 29.46 & 0 \\
Lyon & 35.2 & $39,889^{* *}$ & $15^{*}$ & 0.2 & 26.36 & 6.7 \\
Nice & 35.9 & $39,963^{* *}$ & $15^{*}$ & 0.2 & 3.44 & 11 \\
\hline
\end{tabular}

*: The upper bound has been reached. ${ }^{* *}$ : The near upper bound has been reached. 


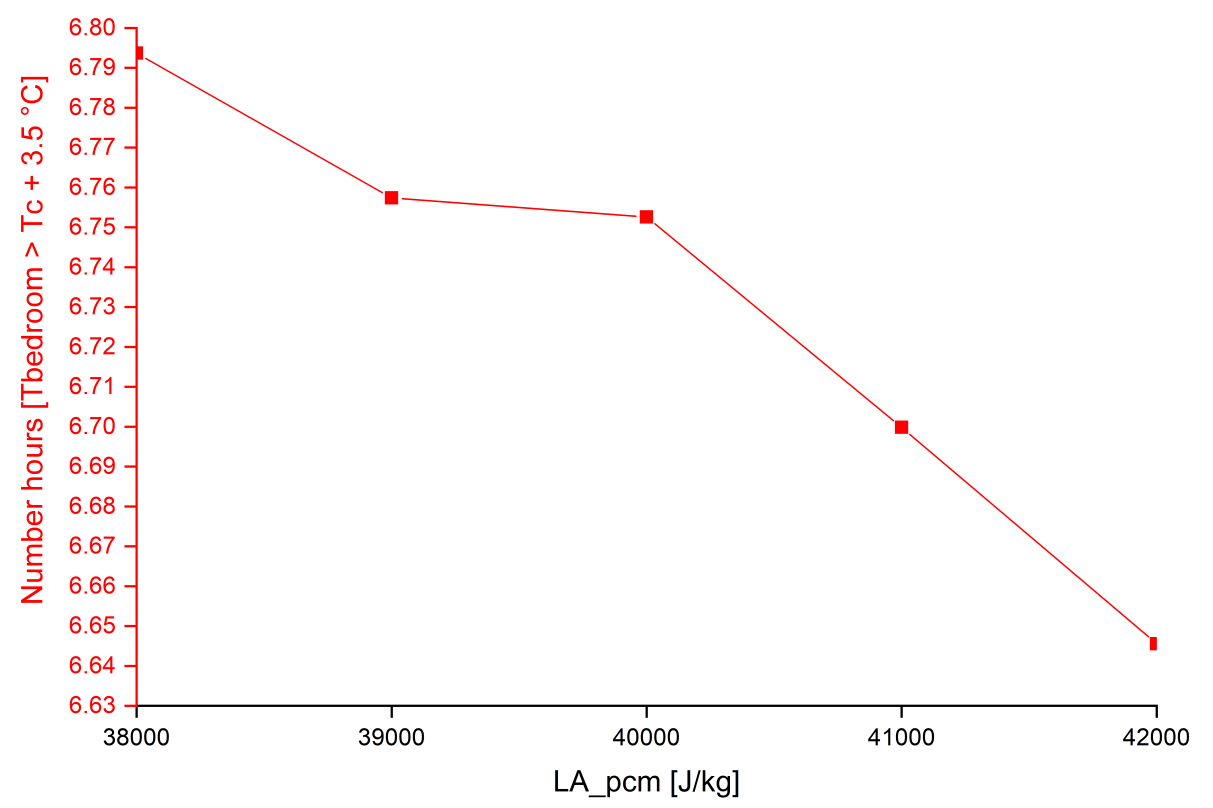

Figure 19. Number of hours of thermal discomfort vs. latent heat parameters lying close to the upper bound of $40,000 \mathrm{~J} / \mathrm{kg}$.

Figure 20 presents the temperature variations inside the bedroom equipped with a solar Trombe wall integrating the optimized PCM for the number of hours of discomfort, across the three temperature curves. The temperature curves, applied with two optimized PCMs, one from the heating demand the other from the number of hours of discomfort, can be explained as follows: the two temperature curves are below and remain less than the bound of the comfort setpoint temperature plus $3.5^{\circ} \mathrm{C}$, as compared to the temperature from the non-optimized PCM; and the temperature curve from the PCM optimized for the number of hours of discomfort is below that for the heating demand, especially on the second day. It can further be assumed that on the second day, the melting temperature was not exceeded in the case of the PCM optimized for the number of hours of discomfort, whereas it was in the case of the PCM optimized for heating demand. This finding is interpreted in Figure 21, which plots temperature variations inside the PCM storage wall.

Figure 22 shows that the power supplied by the solar Trombe wall, installed with the PCM optimized for the number of hours of discomfort, is higher during heating demand (e.g., Day 307 from 12 a.m. to 12 p.m.) compared to that supplied with the non-optimized PCM; moreover, it is lower than that supplied with the PCM optimized for heating demand.

Regarding the obtained results of the number of hours of discomfort objective function, one can conclude that the latent heat and the storage wall thickness correlate with the parametric study given in Section 5; and the melting temperature and the thermal conductivity are independent $\left(32.8^{\circ} \mathrm{C}\right.$ and $0.4 \mathrm{~W} / \mathrm{m} \cdot \mathrm{K}$ from objective function versus $43.8^{\circ} \mathrm{C}$ and $0.2 \mathrm{~W} / \mathrm{m} \cdot \mathrm{K}$ from the parametric study). The bedroom temperature and the power supplied by the solar wall equipped with the optimum PCM of the number of hours of discomfort objective function are smaller than those of the heating demand objective function (Figures 20 and 22). 


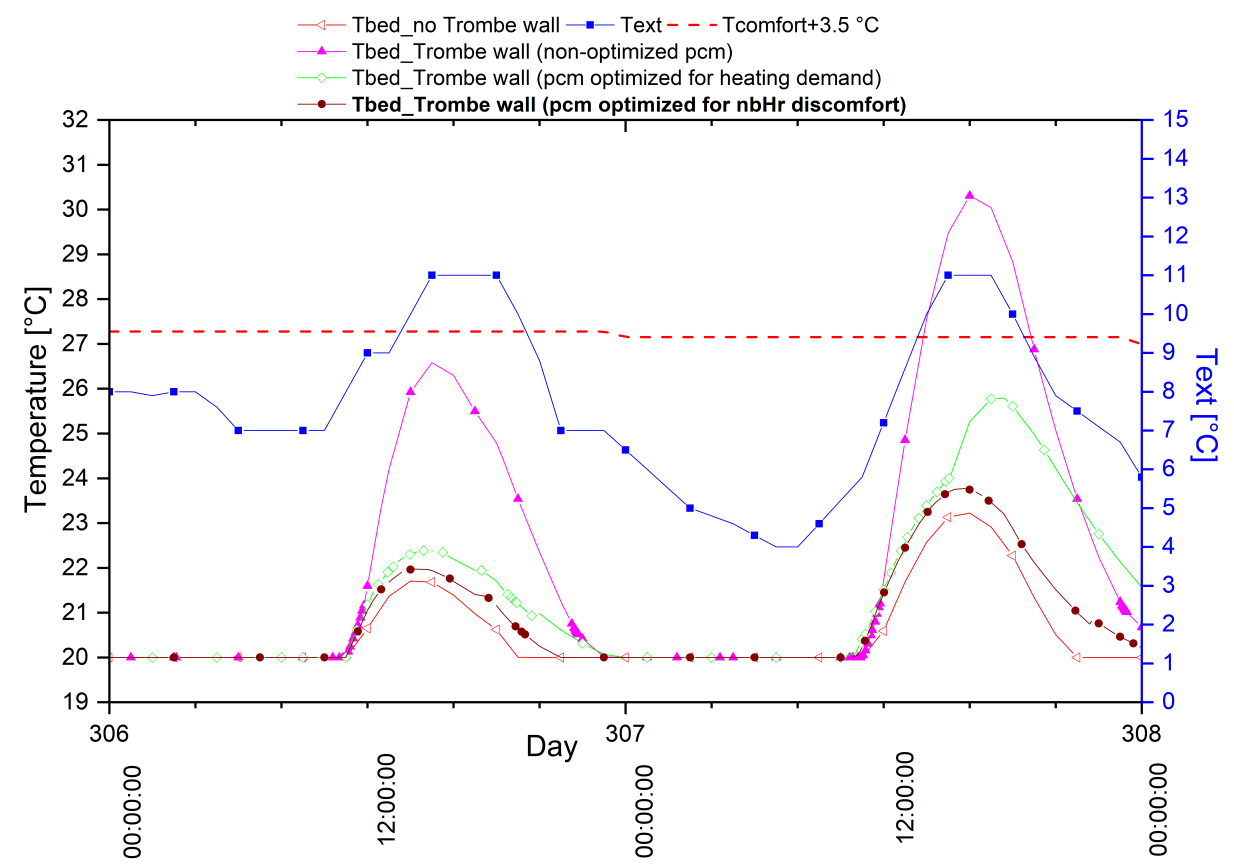

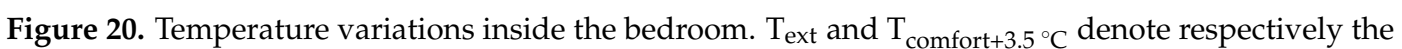
variation in outside air temperature and the comfort setpoint temperature plus $3.5^{\circ} \mathrm{C}$.

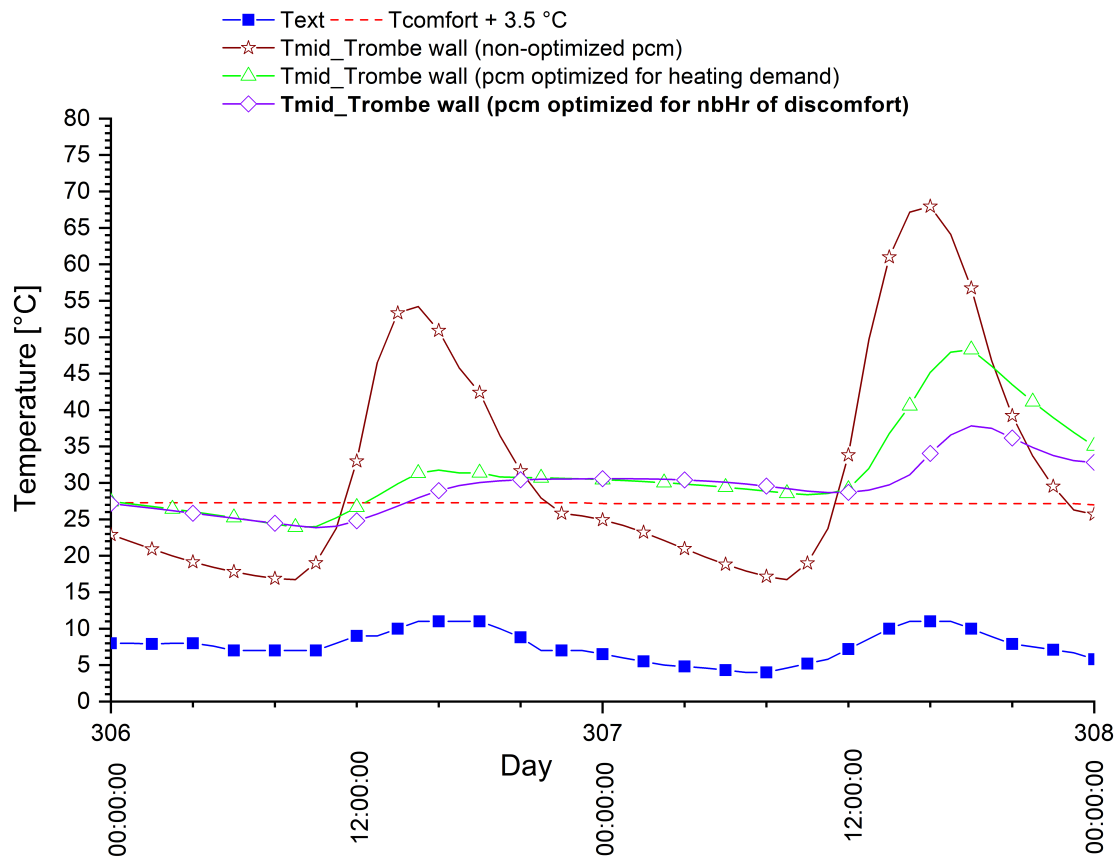

Figure 21. Temperature variations at the center of the PCM storage wall. 


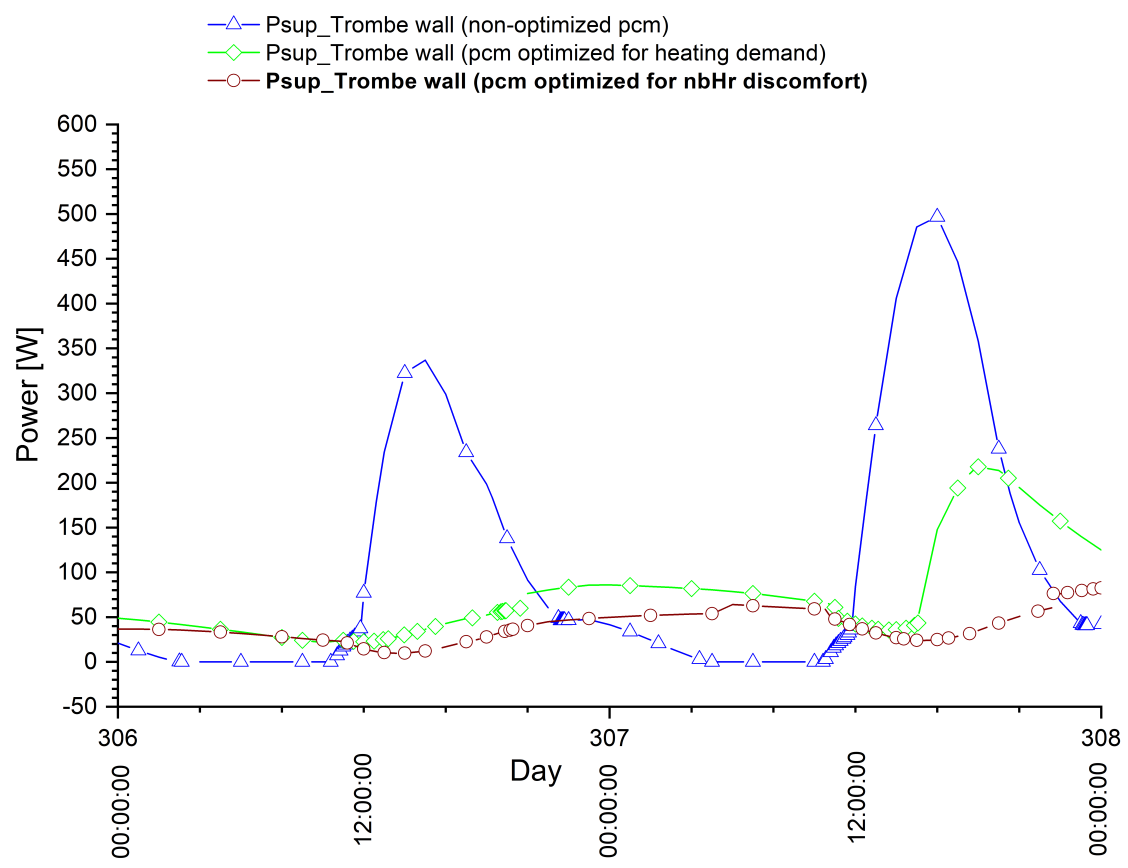

Figure 22. Comparison of the power supplied by the solar Trombe wall installed with the optimized and non-optimized PCM.

\subsection{Simultaneous Optimization of Heating Demand and Number of Hours of Discomfort}

To cope with simultaneously conflicting design criteria (i.e., minimum heating demand vs. maximum thermal comfort), a new optimization approach has been carried out, by coupling both objective functions. The approach employed, commonly known as 'the weighted sum method', is typically applied to solve multi-objective problems. The thermal building simulation tool 'Dymola/Modelica' is used herein to simulate the design house integrating a solar Trombe wall installed with the non-optimized PCM, in the aims of evaluating the reference values of heating demand and number of hours of thermal discomfort. The obtained values will then be input to normalize and be summed with the variable values of heating demand and number of hours of discomfort to yield a single-objective function throughout the optimization run. This simplistic method makes it possible to simultaneously optimize both criteria, with both indicators here having the same weight even though each one can contain biases. The single-objective function is given as follows:

$$
f(X)=\frac{\text { nbHr } \rightarrow \text { T_discomfort }}{(\mathrm{nbHr} \rightarrow \text { T_discomfort })_{\text {ref }}}+\frac{\text { Heating demand }}{(\text { Heating demand })_{\text {ref }}}
$$

Table 9 reports the main results of the optimal parameters derived for the three weather conditions.

Table 9. Optimal parameters, for three weather datasets, from the optimization of the single-objective function.

\begin{tabular}{ccccccc}
\hline Weather & $\begin{array}{c}\mathbf{T M}_{\mathbf{p c m}} \\
{ }^{\circ} \mathbf{C}\end{array}$ & $\begin{array}{c}\mathbf{L A} \mathbf{p c m} \\
\mathbf{J} / \mathbf{k g}\end{array}$ & $\begin{array}{c}\mathbf{e}_{\mathbf{p c m}} \mathbf{c m} \\
\mathbf{W} / \mathbf{m} \cdot \mathbf{K}\end{array}$ & $\begin{array}{c}\lambda_{\mathbf{p c m}} \\
\mathbf{k W h} \cdot \mathbf{m}^{-2} \cdot \mathbf{4} \mathbf{M o n t h s}^{-1}\end{array}$ & $\begin{array}{c}\text { No. Hours Discomfort } \\
\mathbf{h} / \mathbf{4} \text { Months }\end{array}$ \\
\hline Paris & 35.8 & $40,000^{*}$ & $15^{*}$ & 0.733 & 28.57 & 0 \\
Lyon & 34.9 & $40,000^{*}$ & $14.9^{* *}$ & 0.2 & 26.33 & 7.2 \\
Nice & 36 & $39,963^{* *}$ & $15^{*}$ & 0.2 & 3.44 & 11.1 \\
\hline
\end{tabular}

*: The upper bound has been reached. **: The near upper bound has been reached.

The results obtained, like for the previous optimizations, are not the actual optimal values since some optimal parameters did reach their upper bound or near upper bound within the defined 
range: PCM latent heat and thermal conductivity parameters for the optimization of heating demand, and PCM latent heat and storage wall thickness for the optimization of number of hours of discomfort.

The melting temperatures found are higher than those of the two previously optimized objective functions of heating demand (Paris weather) and number of hours of discomfort (weather in Paris, Lyon and Nice). The same values are derived for thermal conductivity under both Lyon and Nice climates, as opposed to the optimized objective function of the number of hours of discomfort. The difference in the optimized thermal conductivity for Paris weather is justified since once the criterion of the number hours of discomfort has reached a zero value, many values of thermal conductivity are surely available to satisfy this criterion.

The new curves of temperature variations in the bedroom and storage wall, as well as in the power supplied, result from the optimized single-objective function (heating demand + no. of hours of discomfort), as included in Figures 23-25. These curves lie close to those derived with the optimized PCM for the number of hours of discomfort. Therefore, it can undoubtedly be interpreted that the optimized number of hours of discomfort is seemingly achievable compared to the optimized heating demand. Based on the results reported in Tables 8 and 9, the heating demands are slightly different (on the order of 5 to $10 \%$ ), whereas the number of hours of discomfort is definitely small and may be neglected.

Regarding the obtained results of the simultaneous optimization, one can conclude that the latent heat and the storage wall thickness correlate with those from the number of hours discomfort objective function and the parametric study given in Section 5; the melting temperature and the thermal conductivity are independent with compared to both cases. The bedroom temperature and the power supplied by the solar wall equipped with the optimum PCM of the simultaneous optimization objective function are slightly different from those of the number of hours of discomfort objective function (Figures 23 and 25).

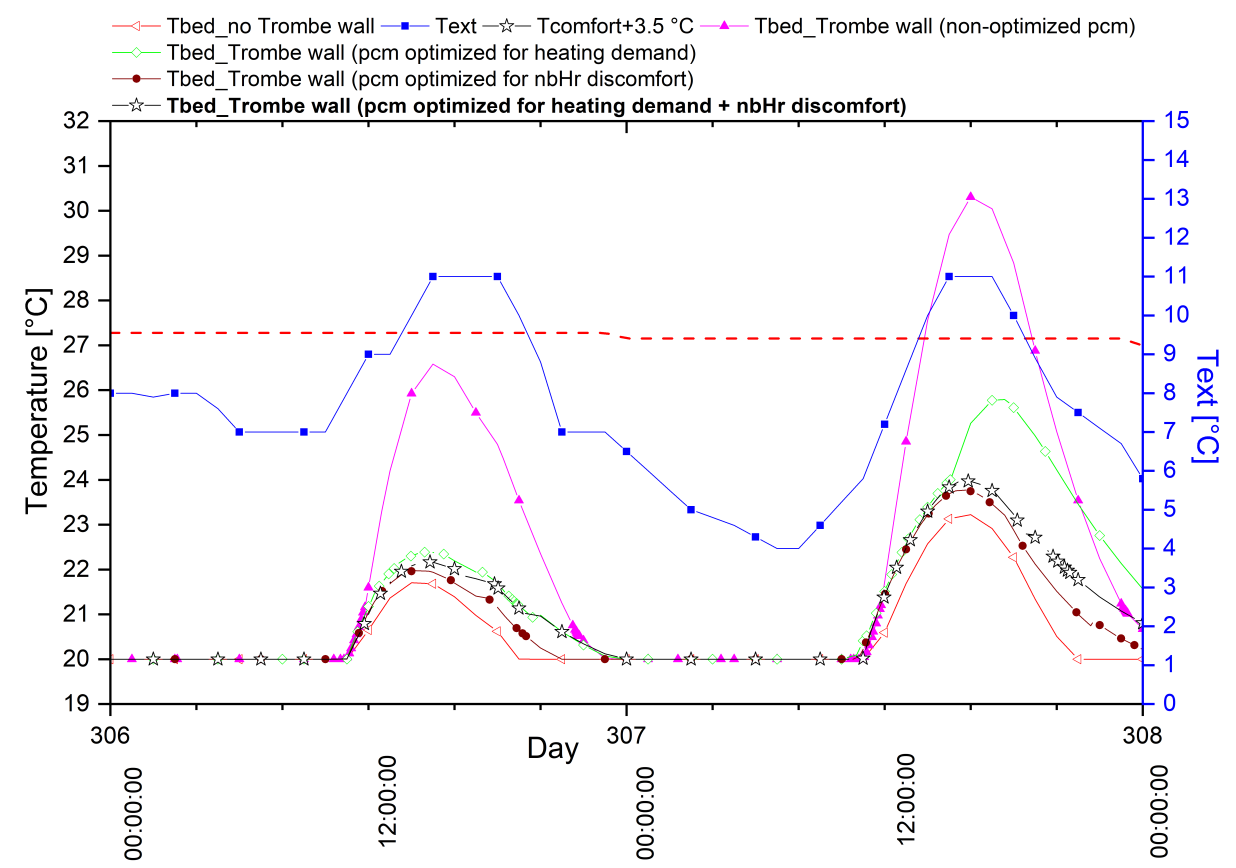

Figure 23. Temperature variations inside the bedroom set up with four different PCM storage walls. 


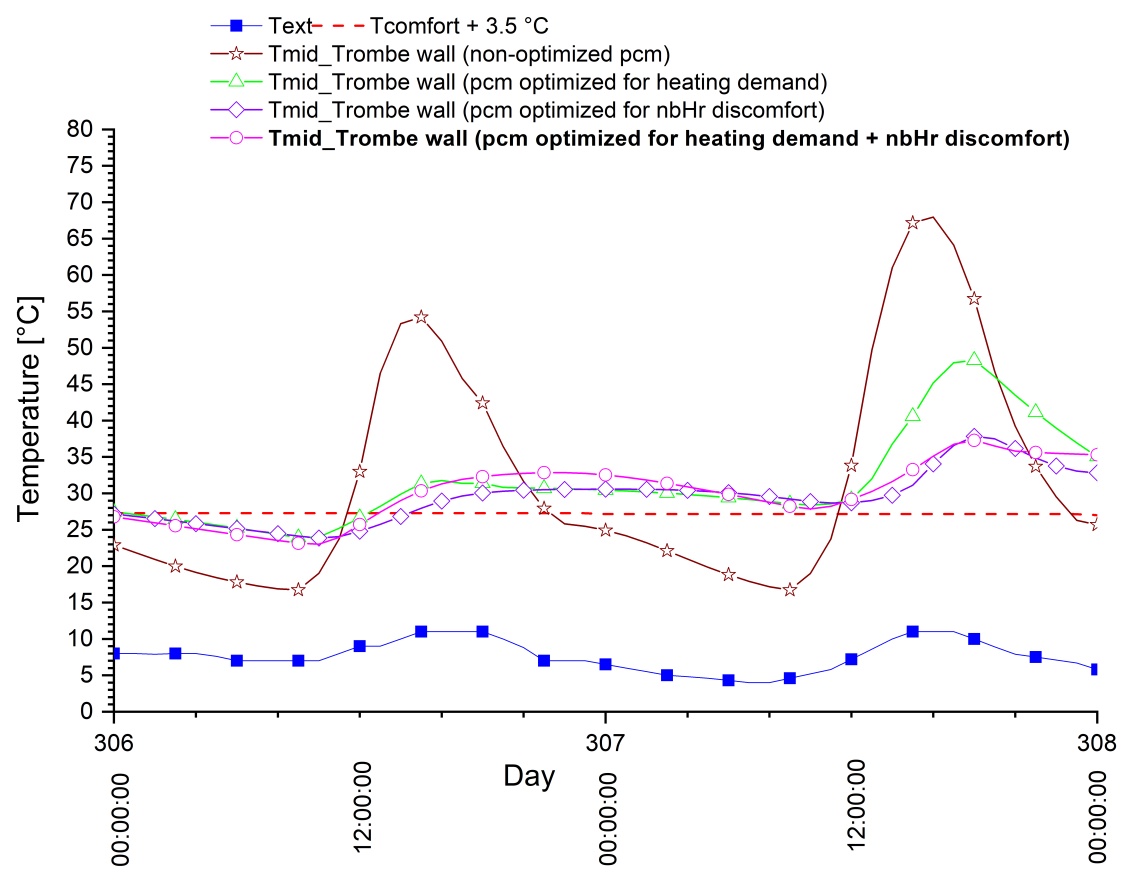

Figure 24. Temperature variations in the PCM storage wall.

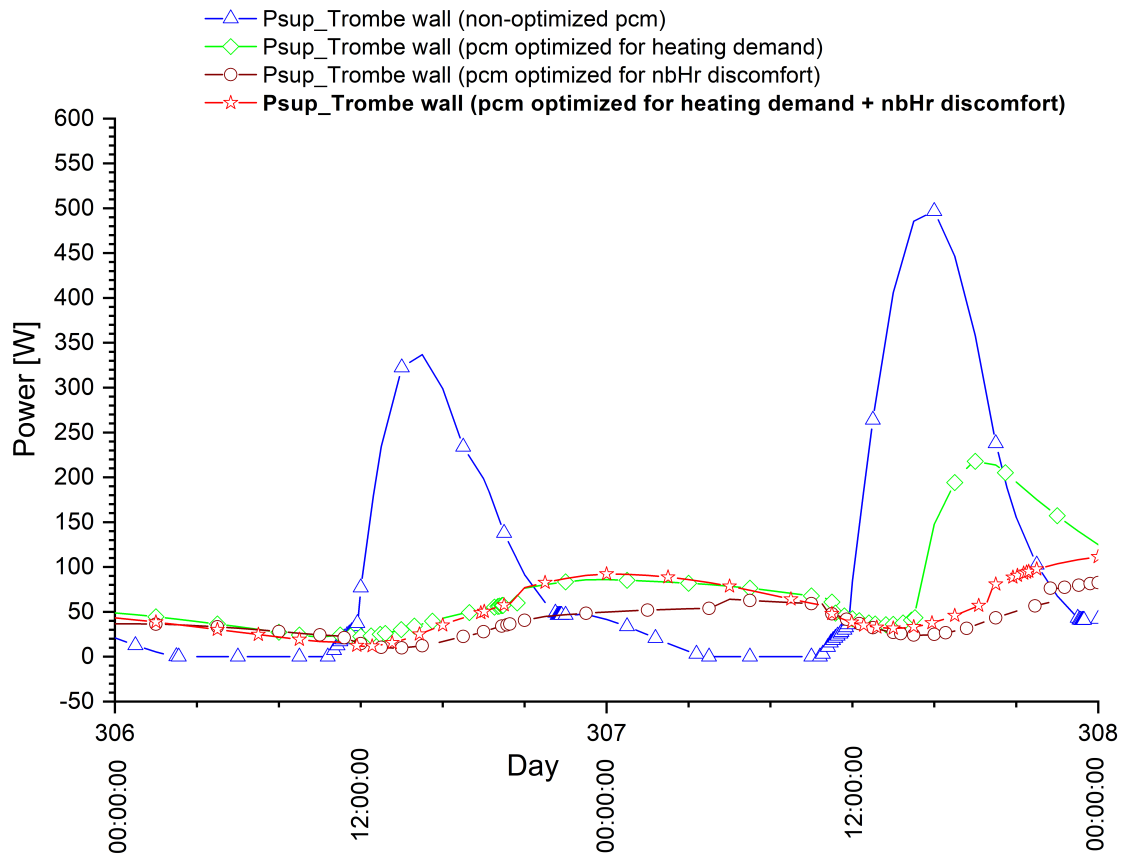

Figure 25. Comparison of the curves of power supplied by the solar Trombe wall.

\section{Conclusions}

After performing the thermal building simulations by varying four PCM parameters, the impacts of these parameters on heating demand, bedroom temperature and temperature within the PCM storage wall could be evaluated independently. Results of the parametric studies on heating demand are limited to roughly $1-2 \mathrm{kWh} \cdot \mathrm{m}^{-2} \cdot \mathrm{year}^{-1}$, whereas the results based on thermal comfort inside the bedroom show the significant impact of PCM compared to that of heating demand. Moreover, results from the parametric study can be summarized by the following statements:

1. The higher the latent heat, the lower the heating demand and the better the thermal comfort in the bedroom, Figure 12; 
2. the optimal melting temperatures are approximately $31{ }^{\circ} \mathrm{C}$ for heating demand and $44{ }^{\circ} \mathrm{C}$ for number of hours of discomfort, Figure 13;

3. the effect of storage wall thickness is small with respect to heating demand, whereas the higher the thickness, the lower the number of hours of discomfort and, thus, the better the thermal comfort, Figure 14;

4. the higher the thermal conductivity, the lower the heating demand and the higher the number of hours of discomfort, Figure 15.

The results obtained relative to the energy supplied by the solar Trombe wall and heating demand are uncorrelated, i.e., these two criteria can either proceed in the same or divergent directions. It would therefore be problematic to design a solar Trombe wall by only considering the energy it supplies during the heating period and not considering an entire simulation of the thermal zone where it was built.

Following the parametric study of these four parameters, the optimization approach applied to three objective functions was subsequently carried out on: the heating demand objective function, the number of hours of discomfort objective function and the single-objective function integrating both of the above. The results yielded no actual optimal values within the defined range, as one or more of the parameters reached the upper or near upper bound. Nevertheless, it is important to underline that the consideration of thermal comfort limits the reduction of heating demand but constrains that the energy contributions must be released with a certain delay, at the time when the heating needs are necessary and not during the day when the solar contributions through the windows directly heat the room.

However, the following can be concluded, based on this optimization approach: the higher the latent heat, the lower the heating demand and the better the thermal comfort, thus confirming the results exposed in Section 5. For the other parameters, with respect to the parametric study, the same has been conformed. Furthermore, the melting temperature increased with application in hotter climates (e.g., Nice); also, the melting temperature was higher for the optimized objective function of the number of hours of discomfort than that of the heating demand.

As for future work, the proposed methodology will be introduced in search of an ideal design, involving:

- development of the mortar + PCM composition with higher latent heat, density and conductivity;

- use of a macro-encapsulated PCM storage wall;

- development of the solar wall relying on the same method, dimensions and location (e.g., living room, with a larger floor area to be heated);

- use of a solar wall for preheating air within the entire house.

Moreover, investigations on additional objective function optimization, including for example environmental impacts, would be significant for the overall energy consumption, which will be a fundamental underlying perspective in the application of PCMs.

Author Contributions: Methodology, E.L., P.T., L.Z. and S.L.; software, E.L. and P.T.; writing-original draft preparation, E.L.; writing—review and editing, P.T., L.Z. and S.L.; visualization, E.L. and P.T.; supervision, P.T., L.Z. and S.L.; funding acquisition, L.Z. All authors have read and agreed to the published version of the manuscript.

Funding: The authors would like to thank the Hauts-de-France Region and the University of Artois for funding Enghok LEANG's doctoral contract.

Acknowledgments: The authors are grateful to BASF for the provision of PCM.

Conflicts of Interest: The authors hereby declare no conflict of interest. This study's financial sponsors played no role in designing the study, nor in the collection, analysis or interpretation of data; nor in writing the manuscript, nor in the decision to publish the results. 


\section{Nomenclature}

Symbols:

C specific heat capacity, J/ kg K

$\mathrm{C}_{\text {solid }} \quad$ specific heat capacity when PCM is in the solid state, $\mathrm{J} / \mathrm{kg} \mathrm{K}$

$\mathrm{C}_{\text {liquid }} \quad$ specific heat capacity when PCM is in the liquid state, $\mathrm{J} / \mathrm{kg} \mathrm{K}$

E energy, $\mathrm{kW} \cdot \mathrm{h}$

e thickness, $\mathrm{m}$

$\mathrm{H}$ height, $\mathrm{m}$

h hour

$\mathrm{L}_{\mathrm{A}} \quad$ latent heat, $\mathrm{J} / \mathrm{kg}$

$\mathrm{nbHr} \quad$ number of hours

no number

$\mathrm{P} \quad$ power supplied by the composite Trombe wall, $\mathrm{W}$

$\mathrm{T} \quad$ temperature, ${ }^{\circ} \mathrm{C}$

$\mathrm{T}_{\mathrm{M}} \quad$ melting temperature, ${ }^{\circ} \mathrm{C}$

$\mathrm{T}_{\mathrm{C}} \quad$ comfort temperature, ${ }^{\circ} \mathrm{C}$

W width, $\mathrm{m}$

Greek symbols

$\begin{array}{ll}\alpha & \text { absorptivity } \\ \varepsilon & \text { emissivity } \\ \lambda & \text { thermal conductivity, W/m K } \\ \phi & \text { flux, } \mathrm{W} / \mathrm{m}^{2} \\ \rho & \text { density, } \mathrm{kg} / \mathrm{m}^{3} \\ \text { Subscripts } & \\ \text { bed } & \text { bedroom } \\ \text { c } & \text { comfort } \\ \text { ext } & \text { exterior } \\ \text { flc } & \text { floor concrete } \\ \text { fr } & \text { frame } \\ \text { glw } & \text { glass wool } \\ \text { hea } & \text { heating } \\ \text { lv } & \text { lower vent } \\ \text { liv } & \text { living room } \\ \text { max } & \text { maximum } \\ \text { mid } & \text { middle } \\ \text { nor } & \text { north-facing rooms } \\ \text { ref } & \text { reference } \\ \text { sal } & \text { salon } \\ \text { sup } & \text { supply } \\ \text { uv } & \text { upper vent } \\ \text { Abbreviations } & \\ \text { M_PCM } & \text { composite material: mortar + PCM } \\ \text { PCM } & \text { phase change material } \\ \text { U } & \text { frame window factor } \\ \end{array}$

\section{References}

1. European Commission. Focus: Energy Efficiency in Buildings. Available online: https:/ / ec.europa.eu/info/ news / focus-energy-efficiency-buildings-2020-feb-17_en (accessed on 23 April 2020).

2. Parliament, E. Guidelines Accompanying Commission Delegated Regulation (EU) No 244/2012 of 16 January 2012. Off. J. Eur. Union 2012, 1-28. 
3. No, R. 244, Commission Delegated Regulation (EU) N. 244/2012 of 16 January 2012 supplementing Directive 2010/31/EU of the European Parliament and of the Council on the energy performance of buildings by establishing a comparative methodology framework for calculating cost-optimal levels of minimum energy performance requirements for buildings and building elements. Off. J. Eur. Union. L 2012, 81.

4. Wetter, M. Simulation Research Group Building Technologies Department Environmental Energy Technologies Division Lawrence Berkeley National Laboratory Berkeley. In Proceedings of the IBPSA's Building Simulation, 2001 Conference, Rio de Janeiro, Brazil, 13-15 August 2001; p. 109.

5. Nguyen, A.T.; Reiter, S.; Rigo, P. A review on simulation-based optimization methods applied to building performance analysis. Appl. Energy 2014, 113, 1043-1058. [CrossRef]

6. Baños, R.; Manzano-Agugliaro, F.; Montoya, F.G.; Gil, C.; Alcayde, A.; Gómez, J. Optimization methods applied to renewable and sustainable energy: A review. Renew. Sustain. Energy Rev. 2011, 15, 1753-1766. [CrossRef]

7. Evins, R. A review of computational optimisation methods applied to sustainable building design. Renew. Sustain. Energy Rev. 2013, 22, 230-245. [CrossRef]

8. Stevanović, S. Optimization of passive solar design strategies: A review. Renew. Sustain. Energy Rev. 2013, 25, 177-196. [CrossRef]

9. Machairas, V.; Tsangrassoulis, A.; Axarli, K. Algorithms for optimization of building design: A review. Renew. Sustain. Energy Rev. 2014, 31, 101-112. [CrossRef]

10. Boeck, L.D.; Verbeke, S.; Audenaert, A.; Mesmaeker, L.D. Improving the energy performance of residential buildings: A literature review. Renew. Sustain. Energy Rev. 2015, 52, 96 -975. [CrossRef]

11. Huang, Y.; Niu, J.l. Optimal building envelope design based on simulated performance: History, current status and new potentials. Energy Build. 2016, 117, 387-398. [CrossRef]

12. Kheiri, F. A review on optimization methods applied in energy-efficient building geometry and envelope design. Renew. Sustain. Energy Rev. 2018, 92, 897-920. [CrossRef]

13. Hashempour, N.; Taherkhani, R.; Mahdikhani, M. Energy performance optimization of existing buildings: A literature review. Sustain. Cities Soc. 2020, 54, 101967. [CrossRef]

14. Dymola-Dassault Systèmes ${ }^{\circledR}$. Library Catalog. Available online: www.3ds.com (accessed on 9 May 2020).

15. Wetter, M.; Group, S.R. GenOpt-Generic Optimization Program, User Manual, V. 3.1.0; LBNL: Berkeley CA, USA, 2011.

16. Attia, S.; Hamdy, M.; O’Brien, W.; Carlucci, C. Computational Optimisation for Zero Energy Building Design, Interviews with Twenty Eight International Experts In Proceedings of the 13th Conference of International Building Performance Simulation Association, Chambéry, France, 25-28 August 2013.

17. EnergyPlus, L. Engineering Reference, the Reference to EnergyPlus Calculations; Ernest Orlando Lawrence Berkeley National Laboratory: Berkeley, CA, USA, 2013.

18. Klein, S.A.; Beckman, W.A.; Mitchell, J.W.; Duffie, J.A.; Duffie, N.A.; Freeman, T.L.; Mitchell, J.C.; Braun, J.E.; Evans, B.L.; Kummer, J.P.; et al. TRNSYS 17-A TRaNsient SYstem Simulation Program, User Manual. Version 17.2.5; University of Wisconsin-Madison: Madison, WI, USA, 2014.

19. Nguyen, A.T.; Reiter, S. Passive designs and strategies for low-cost housing using simulation-based optimization and different thermal comfort criteria. J. Build. Perform. Simul. 2014, 7, 68-81. [CrossRef]

20. Nielsen, T.R. Optimization of Buildings with Respect to Energy and Indoor Environment; Technical University of Denmark (DTU): Kongens Lyngby, Denmark, 2003.

21. Fesanghary, M.; Asadi, S.; Geem, Z.W. Design of low-emission and energy-efficient residential buildings using a multi-objective optimization algorithm. Build. Environ. 2012, 49, 245-250. [CrossRef]

22. Hamdy, M.; Hasan, A.; Siren, K. Applying a multi-objective optimization approach for Design of low-emission cost-effective dwellings. Build. Environ. 2011, 46, 109-123. [CrossRef]

23. Wright, J.A.; Loosemore, H.A.; Farmani, R. Optimization of building thermal design and control by multi-criterion genetic algorithm. Energy Build. 2002, 34, 959-972. [CrossRef]

24. Leang, E.; Tittelein, P.; Zalewski, L.; Lassue, S. Impact of a Composite Trombe Wall Incorporating Phase Change Materials on the Thermal Behavior of an Individual House with Low Energy Consumption. Energies 2020, 13, 4872.10.3390/en13184872. [CrossRef]

25. Bojić, M.; Johannes, K.; Kuznik, F. Optimizing energy and environmental performance of passive Trombe wall. Energy Build. 2014, 70, 279-286. [CrossRef] 
26. Stazi, F.; Mastrucci, A.; Munafò, P. Life cycle assessment approach for the optimization of sustainable building envelopes: An application on solar wall systems. Build. Environ. 2012, 58, 278-288. [CrossRef]

27. Jaber, S.; Ajib, S. Optimum design of Trombe wall system in mediterranean region. Sol. Energy 2011, 85, 1891-1898. [CrossRef]

28. Arıc1, M.; Bilgin, F.; Nižetić, S.; Karabay, H. PCM integrated to external building walls: An optimization study on maximum activation of latent heat. Appl. Therm. Eng. 2020, 165, 114560. [CrossRef]

29. Cascone, Y.; Capozzoli, A.; Perino, M. Optimisation analysis of PCM-enhanced opaque building envelope components for the energy retrofitting of office buildings in Mediterranean climates. Appl. Energy 2018, 211, 929-953. [CrossRef]

30. Xiao, W.; Wang, X.; Zhang, Y. Analytical optimization of interior PCM for energy storage in a lightweight passive solar room. Appl. Energy 2009, 86, 2013-2018. [CrossRef]

31. Park, J.H.; Lee, J.; Wi, S.; Jeon, J.; Chang, S.J.; Chang, J.D.; Kim, S. Optimization of phase change materials to improve energy performance within thermal comfort range in the South Korean climate. Energy Build. 2019, 185, 12-25. [CrossRef]

32. Saffari, M.; Gracia, A.d.; Fernández, C.; Cabeza, L.F. Simulation-based optimization of PCM melting temperature to improve the energy performance in buildings. Appl. Energy 2017, 202, 420-434. [CrossRef]

33. Ascione, F.; Masi, R.F.D.; Rossi, F.d.; Ruggiero, S.; Vanoli, G.P. Optimization of building envelope design for nZEBs in Mediterranean climate: Performance analysis of residential case study. Appl. Energy 2016, 183, 938-957. [CrossRef]

34. Ascione, F.; Bianco, N.; Masi, R.F.D.; Rossi, F.d.; Vanoli, G.P. Energy refurbishment of existing buildings through the use of phase change materials: Energy savings and indoor comfort in the cooling season. Appl. Energy 2014, 113, 990-1007. [CrossRef]

35. Ramakrishnan, S.; Wang, X.; Alam, M.; Sanjayan, J.; Wilson, J. Parametric analysis for performance enhancement of phase change materials in naturally ventilated buildings. Energy Build. 2016, 124, 35-45. [CrossRef]

36. Soares, N.; Gaspar, A.R.; Santos, P.; Costa, J.J. Multi-dimensional optimization of the incorporation of PCM-drywalls in lightweight steel-framed residential buildings in different climates. Energy Build. 2014, 70, 411-421. [CrossRef]

37. Oró, E.; Miró, L.; Farid, M.M.; Martin, V.; Cabeza, L.F. Energy management and $\mathrm{CO}_{2}$ mitigation using phase change materials (PCM) for thermal energy storage (TES) in cold storage and transport. Int. J. Refrig. 2014, 42, 26-35. [CrossRef]

38. Cabeza, L.F.; Miró, L.; Oró, E.; Gracia, A.d.; Martin, V.; Krönauer, A.; Rathgeber, C.; Farid, M.M.; Paksoy, H.O.; Martínez, M.; Fernández, A.I. $\mathrm{CO}_{2}$ mitigation accounting for Thermal Energy Storage (TES) case studies. Appl. Energy 2015, 155, 36 -377. [CrossRef]

39. de Gracia, A.; Barzin, R.; Fernández, C.; Farid, M.M.; Cabeza, L.F. Control strategies comparison of a ventilated facade with PCM-Energy savings, cost reduction and $\mathrm{CO}_{2}$ mitigation. Energy Build. 2016, 130, 821-828. [CrossRef]

40. Asker, M.; Alptekin, E.; Tokuç, A.; Ezan, M.; Ganjehsarabi, H. The effect of phase change material incorporated building wall on the $\mathrm{CO}_{2}$ mitigation: A case study of Izmir, Turkey. Int. J. Glob. Warm. 2019. [CrossRef]

41. Deng, T.; Li, X.; Zhang, L.; Lian, J.; Ma, T.; Wang, Q. Controlling effect of phase change material based heat exchanger on supercritical $\mathrm{CO}_{2}$ Brayton cycle. J. Clean. Prod. 2020, 277, 122994. [CrossRef]

42. Ma, Q.; Fukuda, H.; Wei, X.; Hariyadi, A. Optimizing energy performance of a ventilated composite Trombe wall in an office building. Renew. Energy 2019, 134, 1285-1294. [CrossRef]

43. Bajc, T.; Todorović, M.N.; Svorcan, J. CFD analyses for passive house with Trombe wall and impact to energy demand. Energy Build. 2015, 98, 39-44. [CrossRef]

44. Leang, E.; Tittelein, P.; Zalewski, L.; Lassue, S. Numerical and Experimental Investigations of Composite Solar Walls Integrating Sensible or Latent Heat Thermal Storage. Appl. Sci. 2020, 10, 1854. [CrossRef]

45. Wetter, M.; Bonvini, M.; Nouidui, T.S.; Tian, W.; Zuo, W. Modelica Buildings Library 3.0; In Proceedings of the 14th Conference of International Building Performance Simulation Association, Hyderabad, India, 7-9 December 2015. 
46. Ministry of Urban Planning and Housing. Arrêté du 24 Mars 1982 Relatives a L'aeration des Logements: Aeration Generale ou Permanente, Aeration Permanente Pouvant etre Limitee a Certaines Pieces; Legifrance: France, 1982; R119-2.

47. Zalewski, L.; Franquet, E.; Gibout, S.; Tittelein, P.; Defer, D. Efficient Characterization of Macroscopic Composite Cement Mortars with Various Contents of Phase Change Material. Appl. Sci. 2019, 9, 1104. [CrossRef]

48. Leang, E.; Tittelein, P.; Zalewski, L.; Lassue, S. Numerical study of a composite Trombe solar wall integrating microencapsulated PCM. Energy Procedia 2017, 122, 1009-1014. [CrossRef]

49. Weather Data by Location I EnergyPlus. Available online: https://energyplus.net/weather (accessed on 14 July 2019).

50. McCartney, K.J.; Nicol, J.F. Developing an adaptive control algorithm for Europe. Energy Build. 2002, 34, 623-635. [CrossRef]

51. Stazi, F.; Mastrucci, A.; di Perna, C. The behaviour of solar walls in residential buildings with different insulation levels: An experimental and numerical study. Energy Build. 2012, 47, 217-229. [CrossRef]

Publisher's Note: MDPI stays neutral with regard to jurisdictional claims in published maps and institutional affiliations.

(C) 2020 by the authors. Licensee MDPI, Basel, Switzerland. This article is an open access article distributed under the terms and conditions of the Creative Commons Attribution (CC BY) license (http://creativecommons.org/licenses/by/4.0/). 